\title{
O Comércio Brasil-Mercosul na Década de 90: Uma Análise pela Otica do Comércio Intra-Indústria*
}

\author{
Cláudio Roberto Fóffano Vasconcelos ${ }^{* *}$ \\ Sumário: 1. Introdução; 2. O comércio intra-indústria e sua men- \\ suração para a economia brasileira; 3. Método utilizado na análise \\ do comércio intra-indústria; 4. Resultados; 5 . Considerações finais.
}

Palavras-chave: comércio exterior; comércio intra-indústria; Mercosul.

Códigos JEL: F12; F15.

O presente trabalho objetivou averiguar a contribuição do comércio intra-indústria no crescimento do fluxo comercial brasileiro intraMercosul e se este fluxo de comércio intrabloco seria relativamente mais importante do que extrabloco, para o crescimento do comércio intra-indústria total multilateral. Os resultados apresentados evidenciam que o crescimento do intercâmbio entre o Brasil e os demais países que compõem o MERCOSUL caracterizou-se basicamente pelo incremento no fluxo de comércio intra-indústria.

The object of study of this work is to investigate the contribution of the intra-industry trade to the growth of the Brazilian intrablock trade flow, and if this flow could be relatively more significant than the extra-block to the growth of the total multilateral intraindustry trade. A conclusion is that when analysing the BrazilMERCOSUR bilateral trade flow, an increasing significance of the intra-industry type of trade in this flow was observed.

\section{Introdução}

Segundo Greenaway e Milner (1989, p. 29), "a despeito do fato de que é um consenso entre os teóricos do comércio de que muito do comércio Norte-Sul é explicável dentro de uma estrutura estendida do modelo Heckscher-Ohlin, existe evidência de que uma quantidade significativa de comércio entre países em desenvolvimento (especialmente os de renda mais alta) tem tomado a forma de comércio intra-indústria, especialmente no caso de manufaturados".

\footnotetext{
*Artigo recebido em mar. 2001 e aprovado em abr. 2002. O presente trabalho foi organizado a partir do capítulo 3 da tese de doutorado do autor, apresentada ao PIMES/UFPE.

${ }^{* *}$ Professor adjunto da Fundação Universidade Federal do Rio Grande. E-mail: crfv@mikrus.com.br
} 
Neste contexto de comércio entre países em desenvolvimento, é ressaltado em Vasconcelos (2000, p.p. 5-8) que a composição das pautas de exportações e importações brasileiras, com relação aos demais países do MERCOSUL, se configuraram, para o período entre 1990 a 1998, pela crescente importância em suas composições de produtos industrializados. Isto, de certa forma, denotaria o crescimento do comércio intra-indústria, visto a existência de grupos de produtos semelhantes neste fluxo de comércio.

Portanto, será que, como o esperado pela abordagem do comércio intra-indústria, a implementação do MERCOSUL propiciou o aumento da participação do comércio intra-indústria no fluxo de comércio brasileiro tanto intrabloco quanto extrabloco? Assim, objetiva-se com este trabalho, analisar as alterações ocorridas no comércio intra-industrial brasileiro no sentido de averiguar a contribuição do comércio intra-indústria no crescimento do fluxo comercial brasileiro intrabloco e se este fluxo de comércio intrabloco seria relativamente mais importante do que o extrabloco para o crescimento do comércio intra-indústria total multilateral brasileiro.

Para tanto, o método de abordagem empregado consistiu da mensuração e análise ao longo do tempo do índice de comércio intra-indústria como proposto por Grubel e Lloyd (1975), tanto para o fluxo de comércio intrabloco quanto para o extrabloco. Além dessa, foi empregado também a abordagem proposta por Menon e Dixon (1996) e Menon e Dixon (1997) de mensuração da contribuição do comércio intra-indústria para o crescimento do comércio total brasileiro intrabloco e contribuição do fluxo de comércio intra e extrabloco para o crescimento do fluxo de comércio intra-indústria multilateral brasileiro. A opção pelas duas abordagens deveu-se ao fato de que, como salientado por Menon e Dixon (1996) e Brülhart (1994), a observação da evolução ao longo do tempo do índice de comércio intraindústria de Grubel e Lloyd, pode apresentar algum viés na análise da mudança do padrão (ou de importância) de comércio intra-indústria.

O restante deste trabalho é composto pela seção 2, que faz um apanhado teórico (conceitual e metodológico) do índice de comércio intra-indústria e evidências empíricas de comércio intra-indústria para a economia brasileira; pela 3 onde descreve-se os procedimentos para a mensuração do índice de comércio intraindústria e o desenvolvimento algébrico para a mensuração da contribuição do comércio intra-indústria para o crescimento do fluxo de comércio total brasileiro, tanto intrabloco quanto extrabloco; na 4 são apresentados os resultados obtidos; e, por fim, em 5 as considerações finais. 


\section{O Comércio Intra-indústria e sua Mensuração para a Economia Brasileira}

\subsection{Considerações conceituais e metodológicas}

Conceitualmente, o comércio intra-indústria consiste no comércio, exportação e importação, entre dois países (ou grupos de países) de produtos de um mesmo segmento industrial. Por outro lado, no comércio interindústria o intercâmbio dáse entre diferentes setores de atividade. Formalmente, segundo Grubel e Lloyd (1975, p. 20), o comércio intra-indústria é definido como "o valor das exportações de uma indústria que é exatamente compensado por importações da mesma indústria".

O índice de Grubel e Lloyd (Grubel e Lloyd, 1975) ao nível de cada indústria pode ser representado da seguinte forma:

$$
B_{i}=\frac{\left(X_{i}+M_{i}\right)-\left|X_{i}-M_{i}\right|}{\left(X_{i}+M_{i}\right)} \quad 0 \leq B_{i} \leq 1
$$

onde:

$X_{i}$ e $M_{i}$ representam o valor das exportações e importações da indústria $i$, respectivamente;

$\left(X_{i}+M_{i}\right)$ é o comércio total da indústria $i$;

$\left(X_{i}+M_{i}\right)-\left|X_{i}-M_{i}\right|$ o comércio intra-indústria e, conseqüentemente;

$\left|X_{i}-M_{i}\right|$ é o comércio interindústria.

Em termos agregados seria:

$$
B=1-\frac{\sum_{i}^{n}\left|X_{i}-M_{i}\right|}{\sum_{i}^{n}\left(X_{i}+M_{i}\right)}, \quad \operatorname{com} i=1 \cdots n .
$$

O índice $B$ descrito acima está contido no intervalo $[0,1]$. Quando todo o comércio for explicado pelo comércio interindústria (ou seja, nos moldes do modelo tradicional de $\mathrm{H}-\mathrm{O}$ ), o índice é zero, sendo, nesse caso, ou as exportações ou as importações de cada bem $i$ iguais a zero. Por outro lado, quando todo o comércio for intra-indústria, o índice é igual a um. Nesse caso, o valor das exportações seria igual ao valor das importações de cada bem $i$.

Uma questão comumente salientada na literatura, está relacionada com a agregação dos dados. O que se observa é que quando se trabalha com informações muito agregadas de comércio (como ao nível de um dígito da classificação padrão do 
comércio internacional, SITC), pode ocorrer que a definição de indústria se perca e, por conseguinte, o índice fique sobreestimado, indicando que todo o comércio é intra-industrial. Por outro lado, quando se trabalha com informações muito desagregadas, o índice evidenciaria uma subestimação, pois pode ocorrer separação de mercadorias pertencentes a uma mesma indústria. Portanto, na literatura, observa-se que o mais indicado é o emprego do nível de agregação a três dígitos do SITC.

Várias são as explicações para a existência do comércio intra-indústria. Helpman (1981) e Krugman (1981), entre outros, desenvolvem modelos teóricos sobre a existência do comércio intra-indústria atribuíndo importância à economia de escala e imperfeição de mercado.

Balassa (1986), Bergstrand (1983), Bergstrand (1990), Havrylyshyn e Civan (1983) e Gavelin e Lundberg (1983), além da economia de escala e imperfeição de mercado, consideram na explicação do comércio intra-indústria as características dos países, como igualdade de renda, nível de desenvolvimento econômico, tamanho da economia e nível de tarifas.

Greenaway e Milner (1999) e Greenaway et alii (1995) enfatizam a diferenciação de produtos (diferenciação vertical atribuída à qualidade dos insumos e diferenciação horizontal relacionada à característica de uso do produto ou atributos do produto) na explicação do comércio intra-indústria. A diferenciação horizontal de produtos aumenta quando diferentes variedades de um produto são de certa forma similar na qualidade. Por outro lado, a diferenciação vertical aumenta quando diferentes variedades de produtos têm diferentes finalidades. Portanto, o comércio intra-indústria vertical pode ser relacionado mais a teoria das vantagens comparativas, enquanto o horizontal se enquadra na teoria do comércio intra-indústria.

\subsection{Evidências empíricas de comércio intra-indústria para a eco- nomia brasileira}

Os trabalhos empíricos de verificação do comércio intra-indústria especificamente para a economia brasileira surgiram a partir de meados da década de 80 .

Oliveira (1986), através da mensuração do índice de Grubel e Lloyd, analisa o comércio intra-indústria para a economia brasileira no período de 1969 a 1982, referente a 24 categorias de manufaturados. ${ }^{1}$ Os resultados obtidos pela autora evidenciaram uma tendência crescente do índice de comércio intra-indústria em todo o período de análise, tendo o índice oscilado de 14,3\% em 1969 para 65,4\% em 1982.

\footnotetext{
${ }^{1}$ Ao nível de três dígitos da classificação uniforme do comércio internacional (CUCI).
} 
Segundo a autora, as categorias que apresentaram índice de comércio intraindústria superior a $50 \%$ foram: produtos químicos orgânicos; máquinas para oficina; outras máquinas e aparelhos elétricos; carrocerias, chassis e outras partes para veículos automotores; instrumentos profissionais; aparelhos fotográficos e relógios.

De forma semelhante, Lerda (1988) considerando todos os produtos manufaturados exportados e importados, mensura o índice de comércio intra-indústria de Grubel e Lloyd ${ }^{2}$ para o Brasil referente ao período de 1981 a 1985. Os resultados obtidos são os de que, no fluxo de comércio de produtos manufaturados, o comércio intra-indústria representava 51,11\% em 1981, 47,88\% em 1982, 48,11\% em 1983, 43,01\% em 1984 e 45,82\% em $1985 .{ }^{3}$ Considerando toda a pauta de exportações e importações, os índices de Grubel e Lloyd para o fluxo de comércio global brasileiro foram $26,22 \%, 24,58 \%, 22,52 \%, 20,95 \%$ e $24,52 \%$ para os anos de 1981 a 1985 , respectivamente.

Já Hidalgo (1993) calcula, inicialmente, o índice de comércio intra-indústria entre a economia brasileira e o resto do mundo, através do índice de Grubel e Lloyd, para o período compreendido entre 1978 a $1987 .{ }^{4}$ Os principais resultados são os de que para a economia como um todo, os índices mostram um crescente comércio intra-indústria, variando entre $30 \%$ e $40 \%$ ao longo do período analisado. Com relação ao comércio bilateral entre o Brasil e um conjunto de 56 países, os resultados indicaram que houve um significativo comércio intra-indústria com os países desenvolvidos e com os principais parceiros comerciais da América Latina. Segundo o autor, o comércio intra-indústria com a maioria dos outros países em desenvolvimento mostrou-se insignificante.

Ainda neste trabalho, o autor desenvolveu uma análise dos determinantes do comércio intra-indústria. Os resultados evidenciaram que o comércio intraindústria é mais freqüente nos seguintes grupos de produtos: produtos que são mais diferenciados; produtos que apresentam salários médios mais elevados; produtos onde as barreiras tarifárias são menores; e no comércio com países de renda

\footnotetext{
${ }^{2}$ Calculados por setores de atividade da classificação uniforme de comércio internacional (CUCI), onde foram considerados como produtos manufaturados todas as atividades a 3 dígitos das seções $5,6,7$ e 8 .

${ }^{3}$ Como o índice de Grubel e Lloyd é uma média ponderada, a diferença entre o valor do índice calculado referente as categorias de manufaturados para o ano de 1982, de 65,4\% para Oliveira (1986) e de 47,88\% para Lerda (1988), pode ser explicada pelo fato de que Oliveira trabalha apenas com 24 categorias de produtos manufaturados, enquanto Lerda com toda a pauta de comércio para as atividades classificadas a 3 dígitos para as seções $5,6,7$, e 8 da CUCI.

${ }^{4} \mathrm{O}$ autor utiliza nível de desagregação de três dígitos da Classificação Uniforme do Comércio Internacional (CUCI) e, também, ao nível de capítulos da classificação da Nomenclatura Brasileira de Mercadorias (NBM), para produtos manufaturados.
} 
per capita mediana alta. Esses resultados são para a participação do comércio intra-indústria ao nível de indústria. Para o comércio intra-indústria ao nível de país, as variáveis que mais se destacaram em termos de significância na explicação do comércio intra-indústria foram: tamanho de mercado; média das rendas per capita; e desigualdade da renda per capita entre países.

Albuquerque e Fernandes (1999), buscando analisar os impactos da liberação comercial brasileira pós 1990, mensuram, entre outros índices, o comércio intraindústria através da formulação de Grubel e Lloyd. A construção do índice deu-se especificamente para os anos de 1985, 1990 e 1995, com informações da Matriz de Insumo-Produto do Brasil. Portanto, o nível de agregação das informações foi em termos das atividades da matriz, referindo-se ao comércio total do país com o resto do mundo. As principais conclusões são as de que, apesar do índice de comércio intra-indústria representar $40 \%$ em 1985 e se elevar para $54 \%$ em 1995 , verifica-se que quatorze setores apresentaram tendência de queda ao longo do período analisado. Os aumentos mais expressivos nos índices calculados se referem aos setores de automóveis, indústria têxtil e indústria de vestuário. Esses resultados apresentados pelos autores, de certa forma podem ter sido influenciados (superestimados) pelo nível de agregação utilizado na metodologia da Matriz de Insumo-Produto.

Com relação ao fluxo de comércio brasileiro Brasil-Argentina, Lerda (1988, p. 116) verificou que o índice Grubel e Lloyd para o fluxo de produtos manufaturados foram de 35,35\% em 1981, 29,09\% em 1982, 20,85\% em 1983, 20,61\% em 1984 e 34,77\% em 1985. Especificamente para o ano de 1981, os setores que apresentaram índice de comércio intra-indústria superior a $50 \%$ foram: produtos químicos orgânicos (atividade 512 da CUCI); produtos farmacêuticos e medicinais (541), essências, perfumes, etc. (551), fertilizantes (561); outros produtos químicos não específicos (599); fios e linha (651), vidro (664), formas primárias de ferro e aço (672); veículos a motor para transporte rodoviário (732); suprimentos para fotografia e cinematografia (862); instrumentos musicais, aparelhos gravadores e reprodutores de som, etc. (891).

Em trabalhos recentes, Machado e Markwald $(1997,1998)$ analisam o comércio bilateral entre Brasil e Argentina, preocupando-se com os reflexos do MERCOSUL na evolução do comércio intra-indústria entre esses dois países. Os autores mensuraram o índice de Grubel e Lloyd para o período de 1990 a 1996, e utilizaram informações agregadas ao nível de três dígitos do CUCI-Rev. Na análise da evolução do índice de comércio intra-indústria, as principais conclusões dos autores são as de que o comércio intra-indústria teve uma tendência crescente após a constituição do MERCOSUL, e que este se concentra em apenas duas seções da CUCI, que são 
os produtos químicos e máquinas e material de transporte.

Por fim, quando se trata de um acordo regional de integração como o MERCOSUL, a análise da evolução do índice de comércio intra-indústria ao longo do tempo, como realizado por Lerda (1988), Machado e Markwald (1997, 1998), seria inadequada para se mensurar mudanças importantes no comércio intra-indústria. Pois, segundo Menon e Dixon (1996), a análise do índice ao longo do tempo, não seria capaz de responder a questão relevante de qual seria a contribuição do comércio intra-indústria no crescimento do comércio total.

Neste sentido é que a análise desenvolvida neste capítulo se diferencia dos trabalhos anteriores. Pois ao trabalhar com o fluxo de comércio brasileiro com o MERCOSUL, procurou-se não só verificar a análise da evolução do índice de comércio intra-indústria para o fluxo de comércio intra e extrabloco, mas, principalmente, verificar quanto do aumento do fluxo total de comércio foi devido ao comércio intra-indústria, ou seja, qual a contribuição do comércio intra-indústria para o crescimento do fluxo total de comércio intra e extrabloco.

\section{Método Utilizado na Análise do Comércio Intra-indústria}

Foram empregadas duas abordagens para a análise das mudanças ocorridas no comércio intra-industrial brasileiro, em decorrência da implantação do MERCOSUL. A primeira constituiu-se da análise tradicional da evolução do comércio intra-indústria através do índice proposto por Grubel e Lloyd (1975), e a segunda da contribuição do comércio intra-indústria para a evolução do comércio intrabloco e comércio total, na forma proposta por Menon e Dixon $(1996,1997)$. Assim, pretende-se, com essas duas abordagens, observar com maior acurabilidade as possíveis mudanças no padrão de comércio intra-indústria referente ao intercâmbio comercial brasileiro intra e extrabloco.

Para análise da evolução do comércio intra-indústria, ao longo do tempo, foi realizada a mensuração do comércio intra-indústria brasileiro, tanto intra quanto extrabloco, utilizando o índice de Grubel e Lloyd (1975).

O nível de agregação utilizado foi ao nível de capítulos da nomenclatura de comércio do MERCOSUL (NCM). Portanto, foi utilizada a equação (1) para a mensuração do índice (denominado no texto por $B_{i}$ ) na forma desagregada, em capítulos, e a equação (2) para a agregação em seções (denominado no texto por $B)$. 
A utilização de informação ao nível de agregação de capítulos deve-se à disponibilidade dos dados junto ao sistema de informação da SECEX/MDIC. Esse nível de agregação é bastante semelhante ao nível de agregação a três dígitos da CUCI.

Como a preocupação original é com o crescimento do fluxo de comércio decorrente da constituição do MERCOSUL, foi realizada a mensuração da contribuição do comércio intra-indústria para o crescimento do fluxo total do comércio brasileiro com respeito aos demais países do MERCOSUL. Além disso, foi realizado o estudo do padrão de mudança do comércio brasileiro com destino intra e extrabloco através da mensuração das contribuições destes fluxos de comércio no crescimento do comércio intra-indústria total multilateral brasileiro. Desta forma, nas duas subseções a seguir, foi desenvolvido o procedimento de mensuração dessas contribuições.

\subsection{Mensuração da contribuição do comércio intra-indústria para o crescimento do fluxo comercial brasileiro intrabloco ${ }^{5}$}

Considere, inicialmente, que o comércio total $(C T)$ para o produto $i$ entre o país $j$ e o país (ou grupo de países) $k$ em um ano seja a soma do comércio interindústria $(C E I)$ e o comércio intra-indústria $(C I I)$, então:

$$
C T_{i j k}=C E I_{i j k}+C I I_{i j k}
$$

sendo que:

$$
\begin{gathered}
C T_{i j k}=X_{i j k}+M_{i j k} \\
C E I_{i j k}=\left|X_{i j k}-M_{i j k}\right| \\
C I I_{i j k}=\left(X_{i j k}+M_{i j k}\right)-\left|X_{i j k}-M_{i j k}\right|
\end{gathered}
$$

onde:

$X_{i j k}$ e $M_{i j k}$ são respectivamente as exportações e importações do produto $i$ entre os países $j$ e $k$.

\footnotetext{
${ }^{5}$ Esta seção está baseada em Menon e Dixon (1997, 1996).
} 
Considere agora o índice de comércio intra-indústria como o desenvolvido por Grubel e Lloyd (GL):

$$
G L_{i j k}=\frac{C I I_{i j k}}{C T_{i j k}}
$$

Fazendo a diferencial total da equação (3) e dividindo o resultado por $C T_{i j k}$ obtêm-se a forma da mudança percentual (ou taxa de mudança) no comércio total, então:

$$
\begin{gathered}
d C T_{i j k}=\frac{\partial C T_{i j k}}{\partial C E I_{i j k}} \cdot d C E I_{i j k}+\frac{\partial C T_{i j k}}{\partial C I I_{i j k}} \cdot d C I I_{i j k}=d C E I_{i j k}+d C I I_{i j k} \\
\frac{d C T_{i j k}}{C T_{i j k}}=\frac{d C E I_{i j k}}{C E I_{i j k}} \cdot \frac{C E I_{i j k}}{C T_{i j k}}+\frac{d C I I_{i j k}}{C I I_{i j k}} \cdot \frac{C I I_{i j k}}{C T_{i j k}}
\end{gathered}
$$

Assim, a taxa de crescimento do comércio total $\left(c t_{i j k}\right)$ entre o país $j$ e $k$ para o produto $i$, em um dado período, é dada por:

$$
c t_{i j k}=C c e i_{i j k}+C c i i_{i j k}
$$

onde:

$$
\begin{gathered}
C c e i_{i j k}=(1-G L) \cdot c e i_{i j k} \\
C c i i_{i j k}=G L \cdot c i i_{i j k}
\end{gathered}
$$

sendo:

$c e i_{i j k}$ e $c i i_{i j k}$ a mudança percentual no período do comércio interindústria $(C E I)$ e comércio intra-indústria $(C I I)$, respectivamente.

Desta forma, as equações (11) e (12) mensuram as contribuições do crescimento do comércio interindústria $($ Ccei) e intra-indústria $(C c i i)$ para o crescimento do comércio total. ${ }^{6}$

Essa análise permite, a despeito da observação da evolução do índice de comércio intra-indústria ao longo do tempo ${ }^{7}$, fazer inferências mais precisas sobre a

\footnotetext{
${ }^{6}$ Supondo que $c e i_{i j k}$ seja determinada independentemente de $c i i_{i j k}$, visto que os fatores que determinam o comércio interindústria são diferentes dos que determinam o comércio intraindústria.

${ }^{7}$ Como salienta Menon e Dixon (1996), considerar o movimento, ao longo dos períodos, dos índices de GL como indicador de importância do crescimento do comércio intra-indústria pode
} 
importância do comércio intra-indústria para a expansão do fluxo total de comércio entre o Brasil e os demais países do MERCOSUL, isto é, se a implementação do MERCOSUL promoveu um aumento do comércio intra-indústria na economia brasileira.

\subsection{Comércio intrabloco e extrabloco e a evolução do comércio intra-indústria no Brasil}

De forma semelhante à seção anterior, outra indagação comumente feita é se os acordos regionais de comércio promovem um comércio intra-indústria relativamente mais importante do ponto de vista intrabloco (MERCOSUL) do que extrabloco (resto do mundo). Para responder essa indagação, Shelburne (1994) e Globerman (1992), entre outros, sugerem mensurar o índice de Grubel e Lloyd (GL) para o fluxo de comércio intra e extrabloco. Dessa forma, se o índice GL for maior intrabloco do que para o comércio extrabloco, pode-se inferir que além do acordo de comércio firmado aumentar o comércio intra-indústria entre os países envolvidos, o comércio intrabloco estaria contribuíndo em maior proporção que o comércio extrabloco para o aumento do comércio intra-indústria (CII) do país em questão.

Entretanto, este tipo de abordagem pode apresentar um viés. Segundo Menon e Dixon (1996) este viés estaria refletido no fato de que o comércio intra-indústria total multilateral do país pode não ser igual a soma do comércio intra-indústria intra e extrabloco. ${ }^{8}$ Portanto, comparações entre os índices comércio intra-indústria (índice de Grubel e Lloyd) para o comércio intra e extrabloco podem levar a resultados não condizentes com a realidade.

Com essa preocupação, Menon e Dixon (1996) propõem uma alternativa de análise do CII nos fluxos de comércio intra e extrabloco, ao considerarem a possibilidade de que o comércio desequilibrado intra e extrabloco tenham sinais opostos.

Desta forma, o conceito original de comércio interindústria, na forma da equação (5), fica modificado no sentido de que ele passa a ser igual: primeiro, a di-

apresentar algum viés. Pois, por exemplo, considere que o índice GL esteja aumentando ao longo do tempo, isto ocorrerá se a taxa de crescimento do comércio intra-indústria (cii) estiver crescendo acima da taxa de crescimento do comércio interindústria (cei). Entretanto, sob esta pressuposição, a taxa de crescimento do comércio intra-indústria pode ter uma contribuição relativamente menor para o crescimento do comércio total do produto $i$.

${ }^{8}$ Isto é, quando não se leva em consideração o fato de que o país pode ser, para uma indústria qualquer, importador líquido com relação ao comércio extrabloco e um exportador líquido com relação ao comércio intrabloco, tem-se que o CII total multilateral do país não é igual à soma do CII intra e extrabloco. 
ferença entre exportações e importações, $C E I_{i}=X_{i}-M_{i}$, se e somente se as exportações totais multilaterais forem maiores que as importações totais multilaterais, $X_{i}>M_{i}$; e, segundo, $C E I_{i}=M_{i}-X_{i}$ se e somente se as importações totais multilaterais forem maiores que as exportações totais multilaterais, $M_{i}>X_{i}$. Assim, a soma entre o comércio interindústria intra e extrabloco, $C E I_{i, I N T}$ e $C E I_{i E X T}$ respectivamente, seria igual ao comércio interindústria total multilateral, $C E I_{i}$, para uma indústria $i$ qualquer. Portanto:

$$
C E I_{i}=C E I_{i, I N T}+C E I_{i, E X T}
$$

Considerando que o país seja um importador líquido, $M_{i}>X_{i}$, e fazendo o diferencial total da equação (13) e dividindo o resultado por $C E I_{i}$, tem-se:

$$
c e i_{i}=C c e i_{i, I N T}+C c e i_{i, E X T}
$$

onde:

$c e i_{i}$ é a taxa de crescimento do comércio interindústria total multilateral para a indústria $i$

$C c e i_{i, I N T}$ é a contribuição do comércio intrabloco para o crescimento do comércio interindústria;

$C c e i_{i, E X T}$ é a contribuição do comércio extrabloco para o crescimento do comércio interindústria.

De forma semelhante, para o comércio intra-indústria tem-se:

$$
c i i_{i}=C c i i_{i, I N T}+C c i i_{i, E X T}
$$

para $M_{i}>X_{i}$ :

$$
\begin{gathered}
C c i i_{i, I N T}=\left(\frac{X_{i, I N T}}{X_{i}}\right) \cdot x_{i, I N T} \\
C c i i_{i, E X T}=\left(\frac{X_{i, E X T}}{X_{i}}\right) \cdot x_{i, E X T}
\end{gathered}
$$

e para $M_{i}<X_{i}$ :

$$
C c i i_{i, I N T}=\left(\frac{M_{i, I N T}}{M_{i}}\right) \cdot m_{i, I N T}
$$




$$
C c i i_{i, E X T}=\left(\frac{M_{i, E X T}}{M_{i}}\right) \cdot x_{i, E X T}
$$

onde:

$c i i_{i}$ é a taxa de crescimento do comércio intra-indústria total multilateral para a indústria $i$

$C c i i_{i, I N T}$ a contribuição do comércio intrabloco para o crescimento do comércio intra-indústria;

$C c i i_{i, E X T}$ a contribuição do comércio extrabloco para o crescimento do comércio intra-indústria;

$m_{i, I N T}$ e $m_{i, E X T}$ são as taxas de crescimento das importações intrabloco e extrabloco para a indústria $i$;

$x_{i, I N T}$ e $x_{i, E X T}$ são as taxas de crescimento das exportações intrabloco e extrabloco para a indústria $i$.

Como o foco do presente trabalho é no comércio intra-indústria, foram utilizadas na análise da importância do MERCOSUL para o desempenho do comércio total brasileiro apenas as equações (15), (15a), (15b), (15c) e (15d).

\subsection{Fonte e natureza dos dados}

Para a mensuração do índice de comércio intra-indústria de Grubel e Lloyd, foram utilizadas informações de valores das exportações e importações discriminadas por origem e destino, disponíveis junto à SECEX/MDIC (SECEX, $1994 \mathrm{e}$ 1999a). Estas informações estão disponibilizadas ao nível de seções e capítulos da nomenclatura comum do MERCOSUL (NCM) referente ao fluxo de comércio entre o Brasil e os demais países do MERCOSUL (Argentina, Paraguai e Uruguai).

As informações para o fluxo de comércio brasileiro extrabloco referem-se ao período de 1990 a 1998 e também estão disponibilizadas em seções e capítulos da NCM junto a SECEX/MDIC (SECEX, 1992 e 1999b).

\section{Resultados}

\subsection{Evolução do índice de comércio intra-indústria para o fluxo de comércio entre o Brasil e o MERCOSUL}

Na tabela 1 são apresentados os índices de comércio intra-indústria (equações (1) e (2)) para o fluxo de comércio entre o Brasil e o conjunto dos demais países 
que compõem o MERCOSUL. Já nas tabelas 2 e 3 estão os índices de comércio intra-indústria para o fluxo bilateral de comércio entre o Brasil e Argentina e Brasil e Uruguai, respectivamente. ${ }^{9}$

Os índices de comércio intra-indústria são apresentados por seções e capítulos da NCM para setores industrializados (manufaturados e seminafaturados). Com relação ao índice de comércio intra-indústria para as seções, estas se referem às seções IV até a XVII (exceto as seções XIII - obras de pedras, cerâmicas, vidros - e XIV - pérolas naturais, pedras preciosas). A escolha dessas seções ocorreu primeiro com base no peso de suas participações na pauta de exportações e importações e segundo nos valores dos índices de comércio intra-indústria. Os capítulos da NCM dispostos nas tabelas 1, 2 e 3 se restringe aos capítulos que apresentaram fluxo de comércio superior a US\$ 100 milhões, ou $0,5 \%$ do fluxo total de comércio brasileiro intra-Mercosul em 1998.

Como pode ser observado na tabela 1, o comércio intra-indústria para o intercâmbio entre o Brasil e o MERCOSUL (Argentina, Paraguai e Uruguai conjuntamente), vem crescendo ao longo do tempo, passando de cerca de $46 \%$ em 1994 para cerca de $64 \%$ em 1998. Considerando todo o período, evidencia-se uma tendência crescente do índice de comércio intra-indústria.

As seções que apresentaram índice de comércio intra-indústria superior a $40 \%$ ao longo do período analisado foram: produtos alimentícios, bebidas e fumo (seção IV); produtos das indústrias químicas e conexas (seção VI); plásticos e borracha e suas obras (seção VII); madeira, cortiça e suas obras (IX); matérias têxteis e suas obras (seção XI); calçados, chapéus (seção XII); máquinas e aparelhos, material elétrico (seção XVI); material de transporte (seção XVII) (tabela 1).

As seções X e XII (pasta de madeira, papel e suas obras; calçados e chapéus), apresentaram grande oscilação nos índices ao longo do tempo analisado, não caracterizando, assim, nenhum padrão específico de comércio. Já as seções VI (produtos das indústrias químicas e conexas); VII (plástico e borracha); IX (madeira, cortiça e suas obras); XI (matérias têxteis e suas obras) e XVI (máquinas e aparelhos, material elétrico), apresentaram índices de comércio intra-indústria relativamente estáveis ao longo do tempo. As seções que apresentaram um padrão crescente foram as de material de transporte (XVII) e produtos alimentícios, bebidas e fumo (IV) (tabela 1).

\footnotetext{
${ }^{9}$ O fluxo de comércio entre o Brasil e o Paraguai se apresentou predominantemente interindustrial. Desta forma, estes resultados não foram reportados neste trabalho. Tais resultados encontram-se disponíveis junto ao autor.
} 
Tabela 1

Índice de comércio intra-indústria, por seções e capítulos da NCM, para o fluxo de comércio entre o Brasil e os países do MERCOSUL, 1990 a 1998

\begin{tabular}{|c|c|c|c|c|c|c|c|c|c|}
\hline Seções e capítulos da NCM & 1990 & 1991 & 1992 & 1993 & 1994 & 1995 & 1996 & 1997 & 1998 \\
\hline IV Prod. alimentícios, bebidas e fumo & 0,00 & 0,08 & 0,08 & 0,03 & 0,33 & 0,55 & 0,46 & 0,47 & 0,47 \\
\hline V Produtos minerais & 0,32 & 0,34 & 0,45 & 0,43 & 0,47 & 0,22 & 0,13 & 0,13 & 0,13 \\
\hline 27 Combust. Óleos e ceras minerais & 0,60 & 0,71 & 0,65 & 0,49 & 0,52 & 0,23 & 0,13 & 0,12 & 0,07 \\
\hline VI Prod. indúst. químicas e conexas & 0,60 & 0,67 & 0,66 & 0,52 & 0,52 & 0,53 & 0,57 & 0,58 & 0,63 \\
\hline 28 Produtos químicos inorgânicos & 0,51 & 0,76 & 0,74 & 0,60 & 0,54 & 0,63 & 0,50 & 0,57 & 0,70 \\
\hline 29 Produtos químicos orgânicos & 0,71 & 0,73 & 0,58 & 0,50 & 0,55 & 0,52 & 0,62 & 0,60 & 0,68 \\
\hline 30 Produtos farmacêuticos & 0,00 & 0,00 & 0,00 & 0,00 & 0,96 & 0,97 & 0,81 & 0,75 & 0,85 \\
\hline $\begin{array}{l}32 \text { Extrat. Tanantes e } \\
\text { tintoriais tintas }\end{array}$ & 0,39 & 0,70 & 0,99 & 0,90 & 0,67 & 0,79 & 0,81 & 0,74 & 0,70 \\
\hline VII Plásticos e borracha, e suas obras & 0,73 & 0,41 & 0,44 & 0,36 & 0,47 & 0,69 & 0,68 & 0,46 & 0,73 \\
\hline 39 Plásticos e suas obras & 0,79 & 0,63 & 0,60 & 0,44 & 0,48 & 0,72 & 0,76 & 0,49 & 0,80 \\
\hline 40 Borracha e suas obras & 0,63 & 0,00 & 0,18 & 0,23 & 0,47 & 0,63 & 0,55 & 0,41 & 0,62 \\
\hline VIII Peles, couros, peleteria, e obras & 0,08 & 0,08 & 0,03 & 0,03 & 0,15 & 0,09 & 0,15 & 0,17 & 0,22 \\
\hline 41 Peles (exc. peleteria) e couros & 0,08 & 0,08 & 0,03 & 0,03 & 0,08 & 0,06 & 0,12 & 0,14 & 0,20 \\
\hline IX Madeira, cortiça e suas obras & - & - & - & - & 0,78 & 0,90 & 0,76 & 0,96 & 0,74 \\
\hline X Pasta de madeira, papel es. obras & 0,82 & 0,24 & 0,13 & 0,05 & 0,14 & 0,42 & 0,39 & 0,49 & 0,35 \\
\hline 48 Papel e cartão e suas obras & 0,98 & 0,26 & 0,14 & 0,05 & 0,07 & 0,36 & 0,38 & 0,47 & 0,35 \\
\hline XI Matérias têxteis e suas obras & 0,30 & 0,46 & 0,48 & 0,59 & 0,38 & 0,45 & 0,44 & 0,47 & 0,52 \\
\hline 52 Algodão & 0,20 & 0,35 & 0,50 & 0,49 & 0,35 & 0,37 & 0,37 & 0,42 & 0,59 \\
\hline 54 Filamentos sintéticos ou artificiais & 0,61 & 0,90 & 0,76 & 0,98 & 0,57 & 0,39 & 0,53 & 0,54 & 0,40 \\
\hline XII Calçados, chapéus, etc. & - & - & - & - & 0,18 & 0,91 & 0,86 & 0,81 & 0,49 \\
\hline XV Metais comuns e suas obras & 0,41 & 0,29 & 0,11 & 0,14 & 0,17 & 0,27 & 0,32 & 0,33 & 0,39 \\
\hline 72 Ferro fundido, ferro e aço & 0,29 & 0,05 & 0,03 & 0,05 & 0,10 & 0,08 & 0,16 & 0,25 & 0,26 \\
\hline 73 Obras de ferro fundido, ferro e aço & 0,18 & 0,50 & 0,23 & 0,14 & 0,17 & 0,30 & 0,34 & 0,49 & 0,66 \\
\hline 76 Alumínio e suas obras & 0,92 & 0,64 & 0,21 & 0,26 & 0,43 & 0,63 & 0,62 & 0,42 & 0,42 \\
\hline XVI Máq. e apar., material elétrico & 0,74 & 0,54 & 0,35 & 0,33 & 0,37 & 0,60 & 0,50 & 0,60 & 0,54 \\
\hline 84 Reator nucl., máq. Inst. mecânicos & 0,90 & 0,64 & 0,41 & 0,39 & 0,40 & 0,62 & 0,55 & 0,61 & 0,53 \\
\hline 85 Máquinas apar., material elétrico & 0,32 & 0,29 & 0,15 & 0,15 & 0,30 & 0,54 & 0,35 & 0,60 & 0,56 \\
\hline XVII Material de transporte & 0,44 & 0,45 & 0,34 & 0,57 & 0,72 & 0,96 & 0,96 & 0,97 & 0,93 \\
\hline 87 Veículos autom., tratores, ciclo & 0,45 & 0,45 & 0,34 & 0,57 & 0,72 & 1,00 & 0,97 & 0,98 & 0,93 \\
\hline Total $^{*}$ & 0.48 & 0.48 & 0.35 & 0.40 & 0.46 & 0.59 & 0.56 & 0.61 & 0.64 \\
\hline
\end{tabular}

Fonte: SECEX (1994 e 1999a); cálculos do trabalho.

*Considerando os setores industrializados (semimanufaturados e manufaturados) através das seções de IV a XVII (exceto seções XIII e XIV).

Portanto, se para a economia como um todo, o padrão do fluxo de comércio, em termos de comércio intra-indústria, indica uma trajetória crescente, a análise desagregada evidencia uma certa acomodação dos índices de comércio intra-indústria nos três últimos anos da análise, ou seja, de 1996 a 1998.

$\mathrm{Na}$ análise do fluxo de comércio bilateral Brasil-Argentina (tabela 2), evidenciou-se que a tendência dos índices de comércio intra-indústria permaneceu inalterada em relação à do fluxo de comércio brasileiro com o conjunto dos países pertencentes ao MERCOSUL.

Entretanto, em termos de valores dos índices de comércio intra-indústria, o fluxo bilateral Brasil-Argentina (tabela 2) quando comparado ao fluxo brasileiro com o conjunto dos demais países que compõem o MERCOSUL (tabela 1), apresentou um aumento tanto para as seções IV, VI, VII, XIII, XV, XVI, XVII, XVIII. 
Tabela 2

Índice de comércio intra-indústria, por seções e capítulos da NCM, para o fluxo de comércio entre o Brasil e a Argentina, 1990 a 1998

\begin{tabular}{|c|c|c|c|c|c|c|c|c|c|}
\hline Seções e capítulos da NCM & 1990 & 1991 & 1992 & 1993 & 1994 & 1995 & 1996 & 1997 & 1998 \\
\hline IV Prod. alimentícios, bebidas e fumo & 0,00 & 0,00 & 0,00 & 0,00 & 0,46 & 0,66 & 0,51 & 0,62 & 0,64 \\
\hline V Produtos minerais & 0,22 & 0,17 & 0,24 & 0,23 & 0,25 & 0,09 & 0,06 & 0,05 & 0,08 \\
\hline $\begin{array}{l}27 \text { Combust. Óleos e } \\
\text { e ceras minerais }\end{array}$ & 0,99 & 0,26 & 0,32 & 0,25 & 0,26 & 0,09 & 0,06 & 0,04 & 0,03 \\
\hline $\begin{array}{l}\text { VI Prod. indúst. químicas e } \\
\text { conexas }\end{array}$ & 0,36 & 0,77 & 0,70 & 0,54 & 0,58 & 0,58 & 0,66 & 0,63 & 0,67 \\
\hline 28 Produtos químicos inorgânicos & 0,00 & 0,82 & 0,70 & 0,55 & 0,53 & 0,63 & 0,56 & 0,53 & 0,63 \\
\hline 29 Produtos químicos orgânicos & 0,45 & 0,72 & 0,57 & 0,47 & 0,57 & 0,52 & 0,63 & 0,59 & 0,65 \\
\hline 30 Produtos farmacêuticos & 0,00 & - & - & - & 0,97 & 0,87 & 0,85 & 0,77 & 0,89 \\
\hline $\begin{array}{l}32 \text { Extrat. Tanantes e } \\
\text { tintoriais tintas }\end{array}$ & 0,00 & 0,86 & 0,89 & 0,81 & 0,73 & 0,85 & 0,91 & 0,80 & 0,74 \\
\hline VII Plásticos e borracha, e suas obras & 0,40 & 0,48 & 0,41 & 0,31 & 0,50 & 0,74 & 0,75 & 0,45 & 0,78 \\
\hline 39 Plásticos e suas obras & 0,00 & 0,71 & 0,61 & 0,42 & 0,48 & 0,71 & 0,79 & 0,49 & 0,81 \\
\hline 40 Borracha e suas obras & 0,64 & 0,00 & 0,00 & 0,00 & 0,55 & 0,79 & 0,67 & 0,40 & 0,71 \\
\hline VIII Peles, couros, peleteria, e obras & 0,00 & 0,00 & 0,00 & 0,00 & 0,02 & 0,04 & 0,09 & 0,06 & 0,11 \\
\hline 41 Peles (exc. peleteria) e couros & - & 0,00 & 0,00 & 0,00 & 0,00 & 0,01 & 0,06 & 0,03 & 0,09 \\
\hline IX Madeira, cortiça e suas obras & - & - & - & - & 0,10 & 0,72 & 0,85 & 0,98 & 0,70 \\
\hline X Pasta de madeira, papel e s. obras & 0,34 & 0,26 & 0,09 & 0,06 & 0,16 & 0,48 & 0,39 & 0,47 & 0,33 \\
\hline 48 Papel e cartão e suas obras & 0,77 & 0,28 & 0,09 & 0,06 & 0,09 & 0,43 & 0,38 & 0,44 & 0,33 \\
\hline XI Matérias têxteis e suas obras & 0,02 & 0,82 & 0,42 & 0,79 & 0,33 & 0,45 & 0,43 & 0,43 & 0,50 \\
\hline 52 Algodão & 0,45 & 0,90 & 0,00 & 0,74 & 0,32 & 0,42 & 0,41 & 0,41 & 0,66 \\
\hline 54 Filamentos sintéticos ou artificiais & 0,00 & 0,90 & 0,80 & 0,94 & 0,52 & 0,32 & 0,50 & 0,52 & 0,36 \\
\hline XII Calçados, chapéus, etc. & - & - & - & - & 0,37 & 0,64 & 0,81 & 0,95 & 0,63 \\
\hline $\mathrm{XV}$ Metais comuns e suas obras & 0,16 & 0,38 & 0,14 & 0,19 & 0,15 & 0,29 & 0,34 & 0,34 & 0,41 \\
\hline 72 Ferro fundido, ferro e aço & 0,00 & 0,07 & 0,03 & 0,07 & 0,06 & 0,08 & 0,17 & 0,26 & 0,28 \\
\hline 73 Obras de ferro fundido, ferro e aço & 0,77 & 0,87 & 0,34 & 0,21 & 0,16 & 0,33 & 0,31 & 0,48 & 0,74 \\
\hline 76 Alumínio e suas obras & 0,00 & 0,85 & 0,25 & 0,35 & 0,61 & 0,76 & 0,73 & 0,49 & 0,37 \\
\hline XVI Máq. e apar., material elétrico & 0,30 & 0,70 & 0,42 & 0,42 & 0,46 & 0,76 & 0,61 & 0,68 & 0,60 \\
\hline 84 Reator nucl., máq. Inst. mecânicos & 0,00 & 0,81 & 0,50 & 0,49 & 0,49 & 0,78 & 0,65 & 0,70 & 0,59 \\
\hline 85 Máquinas apar., material elétrico & 0,46 & 0,36 & 0,18 & 0,19 & 0,39 & 0,70 & 0,46 & 0,61 & 0,60 \\
\hline XVII Material de transporte & 0,00 & 0,58 & 0,40 & 0,68 & 0,80 & 0,86 & 0,96 & 0,90 & 0,88 \\
\hline 87 Veículos autom.,tratores, ciclo & 0,00 & 0,58 & 0,40 & 0,68 & 0,81 & 0,86 & 0,96 & 0,90 & 0,88 \\
\hline Total* & 0,23 & 0,52 & 0,37 & 0,44 & 0,49 & 0,58 & 0,59 & 0,61 & 0,65 \\
\hline
\end{tabular}

Fonte: SECEX (1994 e 1999a); cálculos do trabalho.

*Considerando os setores industrializados (semimanufaturados e manufaturados) através das seções de IV a XVII (exceto seções XIII e XIV).

Neste caso, de acordo com a teoria do comércio intra-indústria, quando se trabalha com um nível maior de desagregação, seja em termos de categorias de produtos, como em termos de fluxos de comércio, o esperado é que o índice de comércio intra-indústria tendesse a diminuir. Assim, o desempenho do índice de comércio intra-indústria entre o Brasil e a Argentina verificado foi o contrário do esperado. Entretanto, esse resultado é plenamente justificável, pois os fluxos comerciais entre o Brasil e os países Paraguai e Uruguai são caracterizados pelo comércio interindústria.

Já para o Uruguai, tabela 3, o índice de comércio intra-indústria para o conjunto de seções cresceu significativamente ao longo do período e se estabilizou em torno de $47 \%$ para os anos entre 1996 e 1998. Esses fatos evidenciam que há um certo nível de comércio intra-indústria entre o Brasil e o Uruguai.

Ainda considerando o caso do Uruguai, as seções que apresentaram um padrão crescente de comércio intra-indústria ao longo do período são: produtos das indústrias químicas e conexas (VI); plásticos e borracha e suas obras (VII) e matérias 
têxteis e suas obras (XI). As seções pasta de madeira, papel e suas obras (X), metais comuns e suas obras (XV) e máquinas e aparelhos, material elétrico (XVI), apresentaram picos de comércio intra-indústria acima de $50 \%$ para os anos de 1997 e 1998 (tabela 3). Assim, com relação ao Uruguai, o comércio intra-indústria parece ter se intensificado a partir do ano de 1995.

Por fim, em consonância com o trabalho de Machado e Markwald (1998), os resultados descritos acima para o fluxo de comércio entre o Brasil e a Argentina confirmam sua importância na evolução do comércio intra-indústria brasileiro. Um fato importante a ressaltar, ainda com relação ao fluxo de comércio BrasilArgentina, é o de que de acordo com os resultados de Lerda (1988, p. 116-117), as seções VI (produtos das indústrias químicas e conexas), VII (plásticos e borracha, e suas obras) e XVI (máquinas e aparelhos, material elétrico) já apresentavam, de certa forma, um importante fluxo de comércio intra-indústria nos anos de 1981 e 1985, ou seja, índice de comércio intra-indústria maior que $50 \%$.

Tabela 3

Índice de comércio intra-indústria, por seções e capítulos da NCM, para o fluxo de comércio entre o Brasil e o Uruguai, 1990 a 1998

\begin{tabular}{|c|c|c|c|c|c|c|c|c|c|}
\hline Seções e capítulos da NCM & 1990 & 1991 & 1992 & 1993 & 1994 & 1995 & 1996 & 1997 & 1998 \\
\hline IV Prod. alimentícios, bebidas e fumo & - & - & - & - & 0,26 & 0,32 & 0,20 & 0,23 & 0,16 \\
\hline V Produtos minerais & 0,00 & 0,00 & 0,00 & 0,00 & 0,00 & 0,13 & 0,79 & 0,44 & 0,20 \\
\hline $\begin{array}{l}27 \text { Combust. Óleos } \\
\text { e ceras minerais }\end{array}$ & 0,00 & 0,00 & 0,00 & 0,00 & 0,00 & 0,13 & 0,84 & 0,49 & 0,23 \\
\hline $\begin{array}{l}\text { VI Prod. indúst. químicas e } \\
\text { conexas }\end{array}$ & 0,33 & 0,31 & 0,40 & 0,49 & 0,63 & 0,58 & 0,51 & 0,64 & 0,62 \\
\hline 28 Produtos químicos inorgânicos & 0,00 & 0,00 & 0,00 & 0,00 & 0,83 & 0,72 & 0,29 & 0,99 & 0,65 \\
\hline 29 Produtos químicos orgânicos & 0,90 & 0,85 & 0,72 & 0,72 & 0,21 & 0,43 & 0,54 & 0,72 & 0,84 \\
\hline 30 Produtos farmacêuticos & 0,00 & 0,00 & 0,00 & 0,00 & 0,58 & 0,43 & 0,45 & 0,49 & 0,46 \\
\hline 32 Extrat. Tanantes e tintoriais tintas & 0,32 & 0,37 & 0,82 & 0,83 & 0,90 & 0,81 & 0,92 & 0,91 & 0,91 \\
\hline VII Plásticos e borracha, e suas obras & 0,59 & 0,58 & 0,81 & 0,71 & 0,66 & 0,87 & 0,85 & 0,73 & 0,91 \\
\hline 39 Plásticos e suas obras & 0,72 & 0,68 & 0,78 & 0,72 & 0,67 & 0,96 & 0,94 & 0,70 & 0,97 \\
\hline 40 Borracha e suas obras & 0,38 & 0,00 & 0,89 & 0,71 & 0,64 & 0,67 & 0,64 & 0,79 & 0,79 \\
\hline VIII Peles, couros, peleteria, e obras & 0,11 & 0,33 & 0,16 & 0,12 & 0,24 & 0,27 & 0,38 & 0,38 & 0,58 \\
\hline 41 Peles (exc. peleteria) e couros & 0,11 & 0,33 & 0,16 & 0,12 & 0,27 & 0,35 & 0,54 & 0,45 & 0,67 \\
\hline IX Madeira, cortiça e suas obras & - & - & - & - & 0,01 & 0,00 & 0,06 & 0,07 & 0,08 \\
\hline X Pasta de madeira, papel es. obras & 0,58 & 0,37 & 0,45 & 0,07 & 0,04 & 0,25 & 0,59 & 0,80 & 0,75 \\
\hline 48 Papel e cartão e suas obras & 0,58 & 0,37 & 0,45 & 0,07 & 0,04 & 0,24 & 0,65 & 0,88 & 0,77 \\
\hline XI Matérias têxteis e suas obras & 0,11 & 0,29 & 0,29 & 0,37 & 0,50 & 0,56 & 0,53 & 0,46 & 0,44 \\
\hline 52 Algodão & 0,00 & 0,00 & 0,00 & 0,00 & 0,43 & 0,40 & 0,61 & 0,75 & 0,49 \\
\hline 54 Filamentos sintéticos ou artificiais & 0,78 & 0,90 & 0,10 & 0,05 & 0,45 & 0,46 & 0,42 & 0,54 & 0,68 \\
\hline XII Calçados, chapéus, etc. & - & - & - & - & 0,18 & 0,63 & 0,19 & 0,16 & 0,08 \\
\hline XV Metais comuns e suas obras & 0,00 & 0,00 & 0,00 & 0,00 & 0,24 & 0,36 & 0,43 & 0,54 & 0,53 \\
\hline 72 Ferro fundido, ferro e aço & 0,00 & 0,00 & 0,00 & 0,00 & 0,08 & 0,09 & 0,18 & 0,24 & 0,23 \\
\hline 73 Obras de ferro fundido, ferro e aço & 0,00 & 0,00 & 0,00 & 0,00 & 0,41 & 0,50 & 0,74 & 0,97 & 0,75 \\
\hline 76 Alumínio e suas obras & - & - & - & - & 0,29 & 0,67 & 0,51 & 0,51 & 0,87 \\
\hline XVI Máq. e apar., material elétrico & 0,29 & 0,25 & 0,14 & 0,12 & 0,11 & 0,15 & 0,16 & 0,53 & 0,55 \\
\hline 84 Reator nucl., máq. Inst. mecânicos & 0,31 & 0,20 & 0,12 & 0,14 & 0,09 & 0,10 & 0,12 & 0,20 & 0,34 \\
\hline 85 Máquinas apar., material elétrico & 0,27 & 0,35 & 0,16 & 0,09 & 0,14 & 0,24 & 0,23 & 0,97 & 0,87 \\
\hline XVII Material de transporte & 0,00 & 0,00 & 0,00 & 0,00 & 0,31 & 0,19 & 0,41 & 0,19 & 0,33 \\
\hline 87 Veículos autom.,tratores, ciclo & 0,00 & 0,00 & 0,00 & 0,00 & 0,31 & 0,27 & 0,42 & 0,19 & 0,34 \\
\hline Total* & 0,24 & 0,25 & 0,24 & 0,20 & 0,39 & 0,40 & 0,47 & 0,47 & 0,47 \\
\hline
\end{tabular}

Fonte: SECEX (1994 e 1999a); cálculos do trabalho.

* Considerando os setores industrializados (semimanufaturados e manufaturados) através das seções de IV a XVII (exceto seções XIII e XIV).

Portanto, a análise baseada na evolução ao longo do tempo do índice de 
comércio intra-indústria não responde satisfatoriamente a indagação de que, com a instituição do MERCOSUL, qual seria a contribuição do comércio intra-indústria no crescimento do fluxo de comércio entre o Brasil e os demais países que compõem este acordo de integração econômica. Ou seja, essa análise não revela se o comércio intra-indústria estaria contribuíndo em maior proporção que o comércio interindústria para a evolução do fluxo comércio total brasileiro, com destino aos demais países participantes do MERCOSUL. Desta forma, a despeito da evolução dos índices de comércio intra-indústria verificados, no tópico a seguir procurou-se obter algumas respostas a esta questão.

\subsection{Contribuição do comércio intra-indústria para o crescimento do fluxo de comércio entre o Brasil e o MERCOSUL}

A análise desenvolvida no tópico anterior se baseou na observação da evolução do índice de comércio intra-indústria ao longo do tempo, sendo que a conclusão por esta abordagem é a de que o intercâmbio comercial brasileiro com o MERCOSUL apresentou uma tendência de aumento do comércio intra-indústria.

Entretanto, este tipo de análise pode apresentar um viés. Pois a análise da evolução do índice de comércio intra-indústria pode não ser um indicativo de mudança na importância do comércio intra-indústria para o fluxo de comércio como um todo. Isto é, o índice pode registrar um aumento, ao longo do tempo, a despeito do comércio intra-indústria contribuir proporcionalmente menos que o comércio interindústria para o crescimento do comércio total (Menon e Dixon, 1996, p. 3).

Desta forma, a análise desenvolvida a seguir, de acordo com as equações (10), (11) e (12), visou a mensuração da contribuição do comércio intra e interindústria para o crescimento do comércio total com o MERCOSUL.

As tabelas 4, 5 e 6 apresentam os resultados da mensuração da contribuição do comércio intra e interindústria para o crescimento do fluxo de comércio entre o Brasil e o MERCOSUL, o Brasil e a Argentina e o Brasil e o Uruguai. O Paraguai não foi considerado na análise bilateral em decorrência de seu pequeno nível de comércio intra-indústria com o Brasil, entretanto no fluxo de comércio brasileiro com o MERCOSUL foram considerados os fluxos de comércio brasileiro com Argentina, Paraguai e Uruguai, conjuntamente.

Foram considerados três períodos de tempo: de 1990 a 1992; 1994 a 1996 e 1996 a 1998. Assim, o primeiro período compreende a etapa de implantação do acordo de comércio. O segundo, caracteriza-se pela transição para um mercado 
comum; e o terceiro período refere-se às últimas informações obtidas. ${ }^{10}$ Os setores considerados foram apenas os setores industrializados (manufaturados e semimanufaturados) que apresentaram importância econômica na pauta de intercâmbio de mercadorias. Da mesma forma que o cálculo do índice de comércio intra-indústria, a mensuração da contribuição do comércio intra-indústria no crescimento do fluxo total de comércio, foi realizada ao nível de capítulos e agregado ao nível de seções da NCM. ${ }^{11}$ Os capítulos dispostos nas tabelas 4, 5 e 6 são aqueles que apresentaram volume de comércio superior a $0,5 \%$ (ou US $\$ 100$ milhões) do valor do fluxo total de comércio brasileiro intra-Mercosul em 1998.

Com relação à análise da contribuição do comércio intra-indústria ao crescimento do fluxo total de comércio, para o conjunto de setores considerados, observase que entre 1990 e 1992 a taxa de crescimento do fluxo de comércio total (ct) foi de $119 \%$. Sendo que, desse aumento de $119 \%$, a contribuição do comércio intraindústria (Ccii) foi de apenas $26,82 \%$. Ou seja, a Ccii representou $22,5 \%$ da taxa de crescimento do fluxo total de comércio $(c t)$ e o comércio interindústria (Ccei) representou $77,5 \%$ (tabela 4 ).

De forma contrária, entre 1994 e 1996, a contribuição do comércio intraindústria representou $77,7 \%(37,44$ de 48,19$)$ da taxa de crescimento do fluxo total de comércio. Já entre 1996 e 1998, a taxa de crescimento positiva do fluxo total de comércio decorreu inteiramente do crescimento do comércio intra-indústria, visto que, para esse período, a contribuição do comércio interindústria foi negativa.

Portanto, considerando os setores industrializados como um todo, pode-se inferir que, excluindo os dois primeiros anos de vigência do MERCOSUL, o crescimento do intercâmbio deveu-se basicamente ao incremento no fluxo de comércio intra-indústria. Essa conclusão confirma os resultados encontrados para o índice de comércio intra-indústria (tabela 1), onde se observa que, tanto para o índice global quando para os setores específicos, há uma tendência crescente da importância do comércio intra-indústria para o fluxo de comércio entre o Brasil e os países do MERCOSUL.

\footnotetext{
${ }^{10} \mathrm{O}$ ano de 1993 não foi considerado na análise em decorrência dos perídos escolhidos.

${ }^{11}$ Como salientado anteriormente, as mensurações dessas contribuições somente são válidas se a mudança percentual do comércio intra-indústria for determinada independentemente da mudança percentual do comércio interindústria. O cálculo dos coeficientes de correlação entre essas mudanças percentuais para seções IV a XVIII (ao nível de capítulos) referente aos fluxos de comércio entre Brasil e MERCOSUL, Brasil e Argentina e Brasil e Uruguai foram, respectivamente: $-0.031,-0.041$ e -0.021 para o período de 1990 a $1992 ;-0.095,0.020$ e -0.039 para o período de 1994 a 1996; e $-0.024,-0.066$ e -0.027 para o período de 1996 a 1998. Estes resultados estão condizentes com a teroria, pois indicam que os fatores que determinam o comércio intra-indústria são diferentes dos que determinam o comércio interindústria.
} 
Considerando agora os setores desagregados na forma de seções da NCM, para o período entre 1990 a 1992, tem-se que somente as seções produtos minerais, produtos das indústrias químicas e conexas, e matérias têxteis (seções V, VI e XI, respectivamente) foram as que apresentaram contribuição do comércio intra-indústria superior à contribuição do comércio interindústria (tabela 4). Em comparação com os índices comércio intra-indústria calculados para o fluxo Brasil-MERCOSUL (tabela 1), essas três seções foram as únicas que apresentaram índices crescentes ao longo dos anos de 1990, 1991 e 1992.

Tabela 4

Contribuição do comércio intra-indústria e interindústria para o crescimento do fluxo de comércio entre o Brasil e o Uruguai, em percentual

\begin{tabular}{|c|c|c|c|c|c|c|c|c|c|}
\hline \multirow[b]{2}{*}{ Seções e capítulos da NCM } & \multicolumn{3}{|c|}{1990 a 1992} & \multicolumn{3}{|c|}{1994 a 1996} & \multicolumn{3}{|c|}{1996 a 1998} \\
\hline & ct & Ccii & Ccei & ct & Ccii & Ccei & ct & Ccii & Ccei \\
\hline IV Prod. aliment., bebidas e fumo & - & & - & 164,5 & 27,1 & 137,5 & 58,1 & 5,8 & 52,3 \\
\hline V Produtos minerais & 190,7 & 0,0 & 190,7 & $-68,7$ & 24,7 & $-93,4$ & $-58,1$ & $-70,7$ & 12,6 \\
\hline 27 Comb. óleos e ceras minerais & 202,4 & 0,0 & 202,4 & $-70,0$ & & - & $-66,0$ & $-76,7$ & 10,7 \\
\hline VI Prod. indúst. Quím. e conexas & $-20,5$ & $-1,1$ & $-19,3$ & 62,4 & 20,0 & 42,4 & 1,2 & 11,7 & $-10,6$ \\
\hline 28 Produtos quím. inorgânicos & $-58,0$ & 0,0 & $-58,0$ & 251,5 & 18,1 & 233,5 & $-44,9$ & 6,8 & $-51,6$ \\
\hline 29 Produtos químicos orgânicos & 4,2 & $-15,5$ & 19,7 & 3,8 & 34,8 & $-31,0$ & 9,0 & 37,6 & $-28,6$ \\
\hline 30 Produtos farmacêuticos & 7437 & 0,0 & 7437 & 151,5 & 54,8 & 96,8 & 15,5 & 8,6 & 6,9 \\
\hline 32 Extrat. tanantes tintor. tintas & $-55,8$ & 3,9 & $-59,7$ & 11,2 & 12,5 & $-1,4$ & 31,5 & 27,4 & 4,1 \\
\hline VII Plásticos e borracha e obras & 0,4 & 22,0 & $-21,6$ & 41,7 & 54,4 & $-12,7$ & $-7,9$ & $-1,4$ & $-6,5$ \\
\hline 39 Plásticos e suas o & 10,8 & 13,6 & $-2,8$ & 53,6 & 76,6 & $-23,0$ & $-14,8$ & $-11,0$ & $-3,9$ \\
\hline 40 Borracha e suas obras & $-17,0$ & 36,1 & $-53,0$ & 19,2 & 12,6 & 6,6 & 9,1 & 22,1 & $-13,0$ \\
\hline VIII Peles, & $-71,5$ & $-6,5$ & $-65,0$ & $-5,6$ & 12,1 & $-17,7$ & $-35,0$ & $-0,3$ & $-34,8$ \\
\hline 41 Peles (exc. peleteria) e couros & $-71,5$ & $-6,5$ & $-65,0$ & $-14,1$ & 19,4 & $-33,6$ & $-25,2$ & $-3,6$ & $-21,6$ \\
\hline ortiça e suas obras & & & & $-9,2$ & 5,0 & $-14,2$ & 61,2 & 6,9 & 54,3 \\
\hline X Pasta madeir & 143,7 & 52,1 & 91,6 & 100,4 & 114,6 & $-14,3$ & 26,0 & 35,2 & $-9,2$ \\
\hline 48 Pape & 143,7 & 52,1 & 91,6 & 85,4 & 115,7 & $-30,3$ & 34,5 & 39,2 & $-4,7$ \\
\hline XI Matérias têxteis e suas obras & $-9,1$ & 14,8 & $-23,9$ & 49,8 & 28,9 & 20,9 & $-5,0$ & $-11,1$ & 6,1 \\
\hline 52 Algodão & 63,0 & 0,0 & 63,0 & 13,3 & 25,7 & $-12,5$ & $-8,1$ & $-15,4$ & 7,3 \\
\hline 54 Filamentos sint. ou artificiais & $-12,3$ & $-69,4$ & 57,1 & 42,0 & 15,6 & 26,4 & $-47,8$ & $-6,7$ & $-41,0$ \\
\hline XII Calçados, chapéus, etc. & & & & 40,1 & 8,1 & 32,0 & 24,6 & $-8,4$ & 32,9 \\
\hline $\mathrm{XV}$ Metais con & 76,1 & 0,0 & 76,1 & 27,6 & 30,5 & $-3,0$ & 9,8 & 15,9 & $-6,1$ \\
\hline 72 Ferro fundido, ferro e aço & 58,5 & 0,0 & 58,5 & 4,0 & 11,1 & $-7,1$ & 21,8 & 10,0 & 11,8 \\
\hline $73 \mathrm{Obr}$ & 149,3 & 0,0 & 149,3 & 28,0 & 54,4 & $-26,4$ & $-0,9$ & $-0,3$ & $-0,6$ \\
\hline 76 Alumínic & - & - & - & 61,6 & 53,7 & 7,9 & 44,3 & 74,7 & $-30,3$ \\
\hline XVI Máq. e apar, material elétrico & 21,6 & $-12,5$ & 34,1 & 6,6 & 5,7 & 0,9 & 23,7 & 51,4 & $-27,7$ \\
\hline 84 Reator nucl., máq. Inst. Mec. & 63,9 & $-10,5$ & 74,4 & 28,4 & 6,3 & 22,1 & 17,0 & 27,6 & $-10,6$ \\
\hline 85 Máq. apar., material elétrico & $-22,3$ & $-14,5$ & $-7,7$ & $-18,3$ & 5,0 & $-23,2$ & 35,6 & 94,1 & $-58,5$ \\
\hline XVII Material de transporte & 141,1 & 0,0 & 141,1 & 6,9 & 13,2 & $-6,3$ & 18,7 & $-1,5$ & 20,2 \\
\hline 87 Veículos autom.,tratores,ciclo & 141,1 & 0,0 & 141,1 & 6,7 & 13,3 & $-6,6$ & 19,3 & $-1,6$ & 20,9 \\
\hline $\begin{array}{c}\text { Total } \\
\end{array}$ & 12,7 & 3,1 & 9,6 & 33,1 & 32,4 & 0,7 & 12,4 & 7,2 & 5,2 \\
\hline
\end{tabular}

Fonte: SECEX (1994 e 1999a); cálculos do trabalho.

ct $=$ taxa de crescimento do comércio total;

Ccii = contribuição do comércio intra-indústria para o crescimento do fluxo de comércio total;

Ccei $=$ contribuição do comércio interindústria para o crescimento do fluxo de comércio total.

Em termos da mensuração ao nível de capítulos, o capítulo 27 (combustíveis, óleos e ceras minerais) foi basicamente o responsável pelo resultado obtido na seção V (produtos minerais). Para a seção VI (produtos das indústrias químicas e conexas) os capítulos que contribuíram para esse resultado foram: capítulo 28 
(produtos químicos inorgânicos), 32 (extrato tanantes e tintoriais, tintas). E para a seção XI (matérias têxteis e suas obras) foram os capítulos 52 (algodão) e 54 (filamentos sintéticos ou artificiais) (tabela 4).

Já para os dois períodos subseqüentes analisados, 1994 a 1996, e 1996 a 1998, a situação anterior se inverteu. Das seções consideradas na análise, somente produtos minerais e calçados e chapéus (V e XII), para o período de 1994 a 1996, e as seções pasta de madeira e papel, calçados e chapéus (X e XII), para o período de 1996 a 1998, foram as que apresentaram contribuição do comércio interindústria para o crescimento do comércio total superior a contribuição do comércio intraindústria (tabela 4).

No caso das seções XII, para o período entre 1994 a 1996, e seção X, para 1996 a 1998, se verifica o fato ressaltado por Menon e Dixon $(1996,1997)$ de que aumentos do índice de comércio intra-indústria, necessariamente não significam que o comércio intra-indústria tenha aumentado sua participação no comércio total. Pois o aumento dos índices de comércio intra-indústria para estas seções não confirmou o aumento da participação do comércio intra-indústria no comércio total (tabela 4).

Neste caso, para o período de 1994 a 1996, o capítulo 27 (combustíveis, óleos e ceras minerais) foi o capítulo que determinou o resultado da contribuição do comércio interindústria (Ccei) ser superior à contribuição do comércio intra-indústria (Ccii) para a seção V e os capítulos 66 e 67 para a seção XII.

Da mesma forma, para o período de 1996 a 1998, os capítulos que determinaram o resultado da contribuição do comércio interindústria $(\mathrm{Ccei})$ ser superior à contribuição do comércio intra-indústria (Ccii) foram: 48 (papel e cartão e suas obras) para a seção X (pasta de madeira, papel); e capítulos 64 (calçados, chapéus, etc.), 66 (guarda-chuvas, guarda-sóis, etc) e 67 (penas e penugens preparadas) para a seção XII (calçados, chapéus, etc). ${ }^{12}$

De forma semelhante, na análise da contribuição do comércio intra-indústria (Ccii) para o crescimento do fluxo total de comércio entre o Brasil e a Argentina (tabela 5), observou-se que para o primeiro período considerado, entre 1990 e 1992, a taxa de crescimento do fluxo total de comércio foi de 221,3\% para o conjunto de seções consideradas. Para esse período, a contribuição do comércio intra-indústria foi de $95,2 \%$, representando assim $43 \%$ (95,2 de 221,3) da taxa de crescimento do fluxo total de comércio brasileiro com a Argentina. Já para os dois períodos subseqüentes, de 1994 a 1996, e 1996 a 1998, a contribuição do comércio intra-

\footnotetext{
${ }^{12}$ Os capítulos 64, 66 e 67 não estão reportados nas tabelas 4, 5 e 6 devido ao fato de apresentarem fluxo de comércio inferior a $0,5 \%$ do fluxo total de comércio brasileiro com relação ao MERCOSUL em 1998.
} 
indústria representou $78 \%$ (ou seja, 43,8 de 56,2) e $89 \%$ (23,7 de 26,5) da taxa de crescimento do comércio total para os respectivos períodos. Na análise dos setores agregados na forma de seções da NCM para o fluxo de comércio Brasil-Argentina, verificou-se as mesmas tendências da análise do fluxo de comércio entre o Brasil e o conjunto dos países Argentina, Paraguai e Uruguai.

Tabela 5

Contribuição do comércio intra-indústria e interindústria para o crescimento do fluxo de comércio entre o Brasil e a Argentina, em percentual

\begin{tabular}{|c|c|c|c|c|c|c|c|c|c|}
\hline \multirow[b]{2}{*}{ Seções e capítulos da NCM } & \multicolumn{3}{|c|}{1990 a 1992} & \multicolumn{3}{|c|}{1994 a 1996} & \multicolumn{3}{|c|}{1996 a 1998} \\
\hline & ct & \begin{tabular}{|c|} 
Ccii \\
\end{tabular} & Ccei & ct & \begin{tabular}{|c|} 
Ccii \\
\end{tabular} & Ccei & ct & \begin{tabular}{|c|} 
Ccii \\
\end{tabular} & Ccei \\
\hline IV Prod. aliment., bebidas e fumo & $-4,2$ & 0,0 & $-4,2$ & 58,0 & 33,3 & 24,7 & 5,1 & 16,3 & $-11,2$ \\
\hline V Produtos minerais & 73,1 & 19,8 & 53,3 & 74,2 & $-14,5$ & 88,7 & $-36,3$ & $-0,5$ & $-35,7$ \\
\hline 27 Comb. óleos e ceras minerais & 768,5 & 177,9 & 590,6 & 80,5 & $-16,2$ & 96,7 & $-44,3$ & $-4,1$ & $-40,2$ \\
\hline VI Prod. indúst. Quím. e conexas & 53,5 & 71,2 & $-17,7$ & 57,6 & 45,5 & 12,1 & 28,2 & 20,5 & 7,7 \\
\hline 28 Produtos quím. inorgânicos & - & - & - & 44,3 & 27,5 & 16,9 & 16,4 & 17,6 & $-1,2$ \\
\hline 29 Produtos químicos orgânicos & 24,6 & 25,3 & $-0,7$ & 31,6 & 25,6 & 6,0 & 3,6 & 5,0 & $-1,4$ \\
\hline 30 Produtos farmacêuticos & - & - & - & 211,7 & 167,6 & 44,1 & 67,2 & 63,7 & 3,6 \\
\hline 32 Extrat. tanantes tintor. tintas & - & - & - & 87,1 & 97,9 & $-10,8$ & 32,4 & 6,9 & 25,6 \\
\hline VII Plásticos e borracha e obras & 272,0 & 111,6 & 160,4 & 51,5 & 63,8 & $-12,3$ & 12,6 & 11,9 & 0,7 \\
\hline 39 Plásticos e suas obras & & - & - & 53,9 & 73,9 & $-20,0$ & 12,2 & 11,1 & 1,1 \\
\hline 40 Borracha e suas o & 100,6 & $-64,1$ & 164,7 & 48,4 & 44,4 & 4,0 & 13,3 & 13,7 & $-0,3$ \\
\hline VIII Peles, couros, pelet., e obras & 165,0 & 0,0 & 165,0 & $-8,1$ & 6,5 & $-14,6$ & $-4,5$ & 2,0 & $-6,5$ \\
\hline 41 Peles (exc. peleteria) e couros & & - & - & $-6,3$ & 5,2 & $-11,5$ & $-4,0$ & 2,6 & $-6,6$ \\
\hline IX Madeira, cortiça e suas obras & - & - & - & 81,7 & 145,0 & $-63,3$ & 32,7 & 8,0 & 24,7 \\
\hline $\mathrm{X}$ Pasta made & 129,1 & $-14,3$ & 143,4 & 86,3 & 58,5 & 27,9 & & 2,2 & 24,9 \\
\hline 48 Pape & 392,2 & $-32,3$ & 424,4 & 80,0 & 60,2 & 19,8 & 14,9 & $-0,8$ & 15,7 \\
\hline XI Matérias têxteis e & 137,6 & 62,5 & 86,8 & 46,5 & 40,4 & $-0,4$ & 6,9 & $-7,3$ & \\
\hline 52 Algodão & 944,9 & $-45,2$ & 990,2 & 128,0 & 61,3 & 66,8 & $-27,2$ & 6,9 & $-34,1$ \\
\hline 54 Filamentos sint. ou artificiais & & - & & 78,4 & 37,6 & 40,8 & 10,7 & $-10,2$ & 20,8 \\
\hline XII Calçados, chapéus, etc. & - & - & - & 290,7 & 278,1 & 12,6 & 31,0 & 1,9 & 29,1 \\
\hline $\mathrm{XV}$ Metais comuns e suas obras & 318,9 & 40,6 & 278,3 & 18,3 & 24,8 & $-6,5$ & 32,4 & 20,4 & 12,0 \\
\hline 72 Ferro fundido, ferro e aço & 480,7 & 0,0 & 480,7 & $-14,9$ & 8,9 & $-23,8$ & 46,4 & 24,1 & 22,3 \\
\hline 73 Obras de ferro fund. ferro aço & 167,3 & 13,9 & 153,4 & 42,8 & 27,8 & 15,0 & 39,1 & 72,1 & $-33,0$ \\
\hline 76 Alumínio e suas obras & & & & 139,3 & 114,9 & 24,4 & 13,4 & $-31,3$ & 44,7 \\
\hline XVI Máq. e apar, material elétrico & 179,2 & 87,7 & 91,5 & 42,3 & 39,9 & 2,4 & 19,4 & 10,4 & 8,9 \\
\hline 84 Reator nucl., máq. Inst. Mec. & 514,6 & 309,1 & 205,5 & 46,1 & 46,2 & $-0,1$ & 12,9 & 2,2 & 10,7 \\
\hline 85 Máq. apar., material elétrico & 2,2 & $-28,4$ & 30,5 & 31,8 & 21,7 & 10,1 & 41,1 & 38,0 & 3,0 \\
\hline XVII Material de transporte & 875,9 & - & - & 56,9 & 70,4 & $-13,5$ & 77,5 & 59,7 & 17,8 \\
\hline 87 Veículos autom.,tratores,ciclo & 928,1 & 0,0 & 928,1 & 58,1 & 71,1 & $-13,0$ & 77,6 & 59,7 & 17,9 \\
\hline Total & 221,3 & 95,2 & 126,2 & 56,2 & 43,8 & 12,5 & 26,5 & 23,7 & 2,8 \\
\hline
\end{tabular}

Fonte: SECEX (1994 e 1999a); cálculos do trabalho.

ct $=$ taxa de crescimento do comércio total;

Ccii = contribuição do comércio intra-indústria para o crescimento do fluxo de comércio total;

Ccei $=$ contribuição do comércio interindústria para o crescimento do fluxo

de comércio total.

Desenvolvendo a mesma análise para o fluxo de comércio entre o Brasil e o Uruguai, observa-se que, para o período de 1990 a 1992, a contribuição do comércio intra-indústria representou 24\% (ou seja, 3,1 de 12,7) da taxa de crescimento do fluxo de comércio total para o conjunto de seções consideradas. Para os períodos de 1994 a 1996 e 1996 a 1998, a contribuição do comércio intra-indústria foi de $98 \%(32,4$ de 33,1$)$ e $58 \%(7,2$ de 12,4$)$ do crescimento do fluxo de comércio total entre o Brasil e o Uruguai (tabela 6). 
O resultado para o período de 1996 a 1998, é inferior ao verificado para a Argentina (tabela 5) e para o conjunto dos países que compõem o MERCOSUL (tabela 4$)$.

Tabela 6

Contribuição do comércio intra-indústria e interindústria para o crescimento do fluxo de comércio entre o Brasil e o Uruguai, em percentual

\begin{tabular}{|c|c|c|c|c|c|c|c|c|c|}
\hline \multirow[b]{2}{*}{ Seções e capítulos da NCM } & \multicolumn{3}{|c|}{1990 a 1992} & \multicolumn{3}{|c|}{1994 a 1996} & \multicolumn{3}{|c|}{1996 a 1998} \\
\hline & ct & \begin{tabular}{|l|} 
Ccii \\
\end{tabular} & Ccei & \begin{tabular}{l|l} 
ct & \\
\end{tabular} & Ccii & Ccei & ct & Ccii & Ccei \\
\hline IV Prod. aliment., bebidas e fumo & - & & & 164,5 & 27,1 & 137,5 & 58,1 & 5,8 & 52,3 \\
\hline V Produtos minerais & 190,7 & 0,0 & 190,7 & $-68,7$ & 24,7 & $-93,4$ & $-58,1$ & $-70,7$ & 12,6 \\
\hline 27 Comb. óleos e ceras minerais & 202,4 & 0,0 & 202,4 & $-70,0$ & & & $-66,0$ & $-76,7$ & 10,7 \\
\hline VI Prod. indúst. Quím. e conexas & $-20,5$ & $-1,1$ & $-19,3$ & 62,4 & 20,0 & 42,4 & 1,2 & 11,7 & $-10,6$ \\
\hline 28 Produtos quím. inorgânicos & $-58,0$ & 0,0 & $-58,0$ & 251,5 & 18,1 & 233,5 & $-44,9$ & 6,8 & $-51,6$ \\
\hline 29 Produtos químicos orgânicos & 4,2 & $-15,5$ & 19,7 & 3,8 & 34,8 & $-31,0$ & 9,0 & 37,6 & $-28,6$ \\
\hline 30 Produtos farmacêuticos & 7437 & 0,0 & 7437 & 151,5 & 54,8 & 96,8 & 15,5 & 8,6 & 6,9 \\
\hline 32 Extrat. tanantes tintor. tintas & $-55,8$ & 3,9 & $-59,7$ & 11,2 & 12,5 & $-1,4$ & 31,5 & 27,4 & 4,1 \\
\hline VII Plásticos e borracha e obras & 0,4 & 22,0 & $-21,6$ & 41,7 & 54,4 & $-12,7$ & $-7,9$ & $-1,4$ & $-6,5$ \\
\hline 39 Plásticos e suas obras & 10,8 & 13,6 & $-2,8$ & 53,6 & 76,6 & $-23,0$ & $-14,8$ & $-11,0$ & $-3,9$ \\
\hline 40 Borracha e suas obras & $-17,0$ & 36,1 & $-53,0$ & 19,2 & 12,6 & 6,6 & 9,1 & 22,1 & $-13,0$ \\
\hline VIII Peles, couros, pelet., e obras & $-71,5$ & $-6,5$ & $-65,0$ & $-5,6$ & 12,1 & $-17,7$ & $-35,0$ & $-0,3$ & $-34,8$ \\
\hline 41 Peles (exc. peleteria) e couros & $-71,5$ & $-6,5$ & $-65,0$ & $-14,1$ & 19,4 & $-33,6$ & $-25,2$ & $-3,6$ & $-21,6$ \\
\hline IX Madeira, cortiça e suas o & & & - & $-9,2$ & 5,0 & $-14,2$ & 61,2 & 6,9 & 54,3 \\
\hline X Pasta madeira, papel e obras & 143,7 & 52,1 & 91,6 & 100,4 & 114,6 & $-14,3$ & 26,0 & 35,2 & $-9,2$ \\
\hline $48 \mathrm{~Pa}$ & 143,7 & 52,1 & 91,6 & 85,4 & 115,7 & $-30,3$ & 34,5 & 39,2 & $-4,7$ \\
\hline XI Matérias têxteis e suas obras & $-9,1$ & 14,8 & $-23,9$ & 49,8 & 28,9 & 20,9 & $-5,0$ & $-11,1$ & 6,1 \\
\hline $52 \mathrm{Algc}$ & 63,0 & 0,0 & 63,0 & 13,3 & 25,7 & $-12,5$ & $-8,1$ & $-15,4$ & 7,3 \\
\hline 54 Filamentos sint. ou artificiais & $-12,3$ & $-69,4$ & 57,1 & 42,0 & 15,6 & 26,4 & $-47,8$ & $-6,7$ & $-41,0$ \\
\hline XII Calçados, chapéus, etc. & & - & - & 40,1 & 8,1 & 32,0 & 24,6 & $-8,4$ & 32,9 \\
\hline $\mathrm{XV}$ Metais comuns e suas obras & 76,1 & 0,0 & 76,1 & 27,6 & 30,5 & $-3,0$ & 9,8 & 15,9 & $-6,1$ \\
\hline 72 Ferro $f$ & 58,5 & 0,0 & 58,5 & 4,0 & 11,1 & $-7,1$ & 21,8 & 10,0 & 11,8 \\
\hline 73 Obras de ferro fund. ferro aço & 149,3 & 0,0 & 149,3 & 28,0 & 54,4 & $-26,4$ & $-0,9$ & $-0,3$ & $-0,6$ \\
\hline 76 Alumínio e suas obras & & & - & 61,6 & 53,7 & 7,9 & 44,3 & 74,7 & $-30,3$ \\
\hline XVI Máq. e apar, material elétrico & 21,6 & $-12,5$ & 34,1 & 6,6 & 5,7 & 0,9 & 23,7 & 51,4 & $-27,7$ \\
\hline 84 Reator nucl., mác & 63,9 & $-10,5$ & 74,4 & 28,4 & 6,3 & 22,1 & 17,0 & 27,6 & $-10,6$ \\
\hline 85 Máq. apar., n & $-22,3$ & $-14,5$ & $-7,7$ & $-18,3$ & 5,0 & $-23,2$ & 35,6 & 94,1 & $-58,5$ \\
\hline XVII Material de tran & 141,1 & 0,0 & 141,1 & 6,9 & 13,2 & $-6,3$ & 18,7 & $-1,5$ & 20,2 \\
\hline 87 Veículos autom.,tratores,ciclo & 141,1 & 0,0 & 141,1 & 6,7 & 13,3 & $-6,6$ & 19,3 & $-1,6$ & 20,9 \\
\hline Total & 12,7 & 3,1 & 9,6 & 33,1 & 32,4 & 0,7 & 12,4 & 7,2 & 5,2 \\
\hline
\end{tabular}

Fonte: SECEX (1994 e 1999a); cálculos do trabalho.

ct $=$ taxa de crescimento do comércio total;

Ccii $=$ contribuição do comércio intra-indústria para o crescimento do fluxo de comércio total;

Ccei $=$ contribuição do comércio interindústria para o crescimento do fluxo

de comércio total.

Ainda com relação ao fluxo de comércio entre o Brasil e o Uruguai, as seções que apresentaram contribuição do comércio intra-indústria superior à contribuição do comércio interindústria ao longo dos três períodos de tempo analisados foram as seções VI (produtos das indústrias químicas e conexas), VII (plástico e borracha, e suas obras) e XV (metais comuns e suas obras). As seções X (pasta de madeira, papel) e XVI (máquinas e aparelhos, materiais elétricos) revertem suas posições de forma que, para os períodos de 1994 a 1996 e 1996 a 1998, a contribuição do comércio intra-indústria para o crescimento do fluxo total de comércio passa a ser superior à contribuição do comércio interindústria (tabela 6). 
Desta forma, considerando o fluxo de comércio brasileiro tanto com o conjunto dos demais países que compõem o MERCOSUL (Argentina, Paraguai e Uruguai) quanto com Argentina e Uruguai separadamente, a análise agregada (o conjunto das seções) e a desagregada (cada seção) evidenciaram que a implementação do MERCOSUL acarretou em um aumento significativo da importância do comércio intra-indústria no fluxo de comércio entre o Brasil e os países do MERCOSUL.

Dentro desta análise da importância do comércio intra-indústria no crescimento do fluxo de comércio entre o Brasil e o MERCOSUL, no tópico a seguir se buscou saber se o incremento no comércio intra-indústria total multilateral da economia brasileira, na década de noventa, deveu-se mais ao comércio intra-indústria intrabloco ou ao comércio intra-indústria extrabloco.

\subsection{Evolução do índice de comércio intra-indústria total e extra- bloco brasileiro}

Inicialmente mensurou-se o índice de comércio intra-indústria de Grubel e Lloyd para o fluxo de comércio total multilateral brasileiro (tabela 7) e para o fluxo de comércio entre o Brasil e os demais países que não pertencem ao acordo de comércio do MERCOSUL, denominando este fluxo de comércio como extrabloco (tabela 8). Esses índices foram calculados de acordo com as equações (1) e (2), com informações ao nível de capítulos da NCM. Os capítulos reportados nas tabelas 7 e 8 são aqueles que apresentaram volume de comércio superior a $0,5 \%$ do valor do fluxo total de comércio brasileiro com o resto do mundo em 1998.

Para o fluxo de comércio total brasileiro, os índices de comércio intra-indústria calculados apresentaram, para os anos sob análise, uma tendência crescente para o conjunto de seções selecionadas. O índice de comércio intra-indústria passa de $43 \%$ em 1990, para 48\% e 50\% nos anos de 1997 e 1998, respectivamente (tabela 7).

Por outro lado, para o fluxo de comércio brasileiro extrabloco, o índice de comércio intra-indústria calculado apresentou-se relativamente estável, ao longo do período considerado, tanto no conjunto das seções quanto para as seções selecionadas (tabela 8).

Comparando os resultados das tabelas 8 com os da tabela 1, percebe-se que com relação às seções IV a XVII, o índice de comércio intra-indústria calculado 
para o fluxo de comércio intrabloco foi superior ao índice referente ao fluxo extrabloco em todos os anos da análise.

Tabela 7

Índice de comércio intra-indústria para o fluxo de comércio total multilateral brasileiro

\begin{tabular}{|c|c|c|c|c|c|c|}
\hline Seções e capítulos da NCM & 1990 & 1991 & 1995 & 1996 & 1997 & 1998 \\
\hline IV Prod. aliment., bebidas e fumo & 0,05 & 0,07 & 0,18 & 0,18 & 0,20 & 0,21 \\
\hline V Produtos minerais & 0,25 & 0,21 & 0,19 & 0,17 & 0,16 & 0,17 \\
\hline 26 Minérios, excórias e cinzas & 0,25 & 0,21 & 0,26 & 0,24 & 0,23 & 0,15 \\
\hline 27 Comb. óleos e ceras minerais & 0,22 & 0,17 & 0,13 & 0,11 & 0,09 & 0,13 \\
\hline VI Prod. das indústrias químicas e conexas & 0,69 & 0,65 & 0,56 & 0,55 & 0,54 & 0,52 \\
\hline 28 Produtos químicos inorgânicos & 0,79 & 0,70 & 0,70 & 0,91 & 0,90 & 0,91 \\
\hline 29 Produtos químicos orgânicos & 0,73 & 0,68 & 0,50 & 0,48 & 0,50 & 0,47 \\
\hline 30 Produtos farmacêuticos & 0,36 & 0,39 & 0,34 & 0,27 & 0,26 & 0,28 \\
\hline 31 Adubos e fertilizantes & 0,21 & 0,23 & 0,18 & 0,13 & 0,11 & 0,10 \\
\hline 32 Extrat. tanantes e tintoriais tintas & 0,45 & 0,57 & 0,54 & 0,58 & 0,63 & 0,64 \\
\hline VII Plásticos e borracha e suas obras & 0,91 & 0,91 & 0,76 & 0,73 & 0,74 & 0,70 \\
\hline 39 Plásticos e suas obras & 0,87 & 0,92 & 0,67 & 0,61 & 0,63 & 0,57 \\
\hline 40 Borracha e suas obras & 0,96 & 0,88 & 0,91 & 0,94 & 0,92 & 0,91 \\
\hline VIII Peles, couros, peleteria, e obras & 0,77 & 0,73 & 0,53 & 0,43 & 0,43 & 0,43 \\
\hline 41 Peles (exc. peleteria) e couros & 0,79 & 0,76 & 0,50 & 0,38 & 0,37 & 0,36 \\
\hline IX Madeira, cortiça e suas obras & 0,18 & 0,11 & 0,11 & 0,15 & 0,18 & 0,17 \\
\hline 44 Madeira e suas obras, carvão veg. & 0,18 & 0,11 & 0,10 & 0,15 & 0,18 & 0,17 \\
\hline X Pasta de madeira, papel e obras & 0,40 & 0,43 & 0,55 & 0,62 & 0,62 & 0,64 \\
\hline 47 Pasta de mad., outras mat fibrosas & 0,18 & 0,17 & 0,21 & 0,25 & 0,27 & 0,29 \\
\hline 48 Papel e cartão e suas obras & 0,57 & 0,62 & 0,85 & 0,96 & 0,97 & 0,98 \\
\hline XI Matérias têxteis e suas obras & 0,50 & 0,49 & 0,37 & 0,53 & 0,51 & 0,54 \\
\hline 52 Algodão & 0,62 & 0,62 & 0,31 & 0,44 & 0,42 & 0,55 \\
\hline 54 Filamentos sintét. ou artificiais & 0,76 & 0,65 & 0,22 & 0,34 & 0,32 & 0,29 \\
\hline XII Calçados, chapéus, etc. & 0,05 & 0,07 & 0,25 & 0,22 & 0,23 & 0,16 \\
\hline 64 Calçados, polainas e suas obras & 0,04 & 0,06 & 0,25 & 0,23 & 0,23 & 0,16 \\
\hline $\mathrm{XV}$ Metais comuns e suas obras & 0,25 & 0,24 & 0,37 & 0,37 & 0,48 & 0,50 \\
\hline 72 Ferro fundido, ferro e aço & 0,12 & 0,08 & 0,15 & 0,15 & 0,22 & 0,25 \\
\hline 73 Obras de ferro fundido, ferro aço & 0,58 & 0,54 & 0,77 & 0,87 & 0,93 & 0,85 \\
\hline 76 Alumínio e suas obras & 0,17 & 0,14 & 0,39 & 0,41 & 0,51 & 0,64 \\
\hline 82 Ferramentas, artefatos cutelaria & 0,84 & 0,87 & 0,95 & 0,64 & 0,92 & 0,95 \\
\hline XVI Máquinas e aparelhos, material elétrico & 0,81 & 0,84 & 0,57 & 0,54 & 0,48 & 0,49 \\
\hline 84 Reator nucl. maq. inst. mecânic. & 0,87 & 0,91 & 0,68 & 0,64 & 0,57 & 0,58 \\
\hline 85 Máquinas apar., mats. elétricos & 0,68 & 0,71 & 0,40 & 0,37 & 0,35 & 0,36 \\
\hline XVII Material de transporte & 0,49 & 0,62 & 0,65 & 0,86 & 0,90 & 0,91 \\
\hline 87 Veículos autom., tratores, ciclo & 0,41 & 0,56 & 0,63 & 0,87 & 0,92 & 0,94 \\
\hline 88 Aeronave, out. ap. aéreos partes & 0,73 & 0,90 & 0,98 & 0,96 & 0,90 & 0,85 \\
\hline \multicolumn{2}{|l|}{$\begin{array}{l}\text { Total (Seções IV a XVII) } \\
\end{array}$} & 0,44 & 0,45 & 0,46 & 0,48 & 0,50 \\
\hline
\end{tabular}

De forma desagregada, observa-se que o índice de comércio intra-indústria calculado para o fluxo de comércio brasileiro intrabloco (tabela 1), foi maior que o índice de comércio intra-indústria (tabela 8) calculado referente ao fluxo extrabloco nos anos de 1995 a 1998 nas seguintes seções: produtos das indústrias químicas e conexas (VI); plásticos e borracha (VII); máquinas e aparelhos e material elétrico (XVI); e material de transporte (XVII). Um fato importante foi que, para essas mesmas seções, o índice calculado referente ao fluxo extrabloco foi maior que o índice para o fluxo intrabloco nos anos de 1990 e 1991. Este fato caracterizaria assim, uma mudança no padrão do fluxo de comércio nestas seções com a implementação do MERCOSUL. 
Tabela 8

Índice de comércio intra-indústria para o fluxo de comércio brasileiro extra-MERCOSUL

\begin{tabular}{|c|c|c|c|c|c|c|}
\hline Seções e capítulos da NCM & 1990 & 1991 & 1995 & 1996 & 1997 & 1998 \\
\hline IV Prod. aliment., bebidas e fumo & 0,04 & 0,05 & 0,14 & 0,13 & 0,14 & 0,14 \\
\hline V Produtos minerais & 0,24 & 0,20 & 0,19 & 0,18 & 0,16 & 0,18 \\
\hline 26 Minérios, excórias e cinzas & 0,25 & 0,21 & 0,27 & 0,25 & 0,24 & 0,15 \\
\hline 27 Comb. óleos e ceras minerais & 0,21 & 0,16 & 0,11 & 0,11 & 0,08 & 0,14 \\
\hline VI Prod. das indústrias químicas e conexas & 0,66 & 0,61 & 0,44 & 0,44 & 0,42 & 0,41 \\
\hline 28 Produtos químicos inorgânicos & 0,81 & 0,69 & 0,60 & 0,80 & 0,82 & 0,83 \\
\hline 29 Produtos químicos orgânicos & 0,69 & 0,63 & 0,41 & 0,41 & 0,42 & 0,40 \\
\hline 30 Produtos farmacêuticos & 0,36 & 0,40 & 0,23 & 0,19 & 0,17 & 0,18 \\
\hline 31 Adubos e fertilizantes & 0,14 & 0,14 & 0,00 & 0,00 & 0,01 & 0,01 \\
\hline 32 Extrat. tanantes e tintoriais tintas & 0,46 & 0,54 & 0,43 & 0,46 & 0,49 & 0,49 \\
\hline VII Plásticos e borracha e suas obras & 0,93 & 0,97 & 0,60 & 0,55 & 0,39 & 0,54 \\
\hline 39 Plásticos e suas obras & 0,88 & 0,99 & 0,47 & 0,41 & 0,27 & 0,38 \\
\hline 40 Borracha e suas obras & 0,99 & 0,95 & 0,79 & 0,78 & 0,60 & 0,78 \\
\hline VIII Peles, couros, peleteria, e obras & 0,39 & 0,33 & 0,26 & 0,24 & 0,25 & 0,26 \\
\hline 41 Peles (exc. peleteria) e couros & 0,37 & 0,32 & 0,20 & 0,16 & 0,16 & 0,15 \\
\hline IX Madeira, cortiça e suas obras & 0,05 & 0,03 & 0,03 & 0,05 & 0,09 & 0,10 \\
\hline 44 Madeira e suas obras, carvão veg. & 0,05 & 0,03 & 0,03 & 0,05 & 0,09 & 0,10 \\
\hline X Pasta de madeira, papel e obras & 0,36 & 0,44 & 0,56 & 0,54 & 0,53 & 0,50 \\
\hline 47 Pasta de mad., outras mat fibrosas & 0,16 & 0,16 & 0,20 & 0,24 & 0,23 & 0,22 \\
\hline 48 Papel e cartão e suas obras & 0,53 & 0,67 & 0,95 & 0,89 & 0,89 & 0,82 \\
\hline XI Matérias têxteis e suas obras & 0,30 & 0,31 & 0,27 & 0,52 & 0,44 & 0,44 \\
\hline 52 Algodão & 0,19 & 0,24 & 0,18 & 0,51 & 0,42 & 0,52 \\
\hline 54 Filamentos sintét. ou artificiais & 0,83 & 0,46 & 0,18 & 0,28 & 0,24 & 0,25 \\
\hline XII Calçados, chapéus, etc. & 0,05 & 0,07 & 0,21 & 0,18 & 0,18 & 0,12 \\
\hline 64 Calçados, polainas e suas obras & 0,04 & 0,06 & 0,21 & 0,18 & 0,18 & 0,12 \\
\hline XV Metais comuns e suas obras & 0,25 & 0,24 & 0,36 & 0,35 & 0,43 & 0,46 \\
\hline 72 Ferro fundido, ferro e aço & 0,11 & 0,09 & 0,16 & 0,15 & 0,21 & 0,25 \\
\hline 73 Obras de ferro fundido, ferro aço & 0,60 & 0,54 & 0,89 & 0,98 & 0,83 & 0,75 \\
\hline 76 Alumínio e suas obras & 0,16 & 0,13 & 0,37 & 0,39 & 0,52 & 0,66 \\
\hline 82 Ferramentas, artefatos cutelaria & 0,83 & 0,89 & 0,79 & 0,51 & 0,68 & 0,75 \\
\hline XVI Máquinas e aparelhos, material elétrico & 0,79 & 0,80 & 0,48 & 0,44 & 0,39 & 0,40 \\
\hline 84 Reator nucl. maq. inst. mecânic. & 0,86 & 0,87 & 0,59 & 0,55 & 0,47 & 0,48 \\
\hline 85 Máquinas apar., mats. elétricos & 0,65 & 0,65 & 0,32 & 0,30 & 0,27 & 0,29 \\
\hline XVII Material de transporte & 0,50 & 0,65 & 0,54 & 0,77 & 0,85 & 0,89 \\
\hline 87 Veículos autom., tratores, ciclo & 0,41 & 0,59 & 0,50 & 0,75 & 0,88 & 0,94 \\
\hline 88 Aeronave, out. ap. aéreos partes & 0,73 & 0,90 & 0,97 & 0,96 & 0,89 & 0,85 \\
\hline Total (Seções IV a XVII) & 0,40 & 0,41 & 0,37 & 0,38 & 0,39 & 0,41 \\
\hline
\end{tabular}

Fonte: Cálculos do trabalho e SECEX (1992 e 1999b) e

Secretaria da Receita Federal (1990 e 1991); cálculos do trabalho.

Portanto, com base na análise da evolução do índice de comércio intra-indústria referente ao fluxo de comércio intra e extrabloco ao longo do tempo, pode-se dizer que, para a economia brasileira, a implementação do MERCOSUL além de ter propiciado um crescimento do comércio intra-indústria intrabloco, também propiciou que este fluxo de comércio passasse a contribuir relativamente mais que o comércio extrabloco para o crescimento do comércio intra-indústria total multilateral brasileiro.

\subsection{Contribuição do comércio intra-MERCOSUL e extra-MERCO- SUL para a evolução do comércio intra-indústria total no Bra- sil}

Como ressaltado na seção 3.2, a análise anterior da evolução dos índices de comércio intra-indústria com relação ao fluxo intra e extrablco pode apresentar 
um viés. Pois a simples mensuração do índice de comércio intra-indústria não leva em consideração a possibilidade de existência de sinais opostos no fluxo de comércio extrabloco e o comércio intrabloco. Logo, a soma do comércio intra-indústria total pode não ser igual a soma do comércio intra-indústria intra e extrabloco.

Desta forma, nesta seção do trabalho procedeu-se à mensuração da contribuição do fluxo de comércio brasileiro intra e extra-MERCOSUL no crescimento do comércio intra-indústria total multilateral, utilizando a abordagem descrita no tópico 3.2, que leva em consideração a possibilidade de existência de sinais opostos no comércio desequilibrado intra e extrabloco.

Para fins de comparação, foram considerados dois intervalos de tempo: de 1991 a 1995 e 1995 a 1998. Neste caso, as informações originais expressas em valores FOB e em dólar americano, foram transformadas em valores constantes para o ano base de 1995 tomando como proxy para a inflação mundial o índice de preços por atacado dos Estados Unidos.

Assim, os resultados da contribuição dos fluxos de comércio brasileiro intra e extra-MERCOSUL para o crescimento do comércio intra-indústria total brasileiro estão descritos na tabela 9 , de acordo com a equação (15).

Portanto, considerando a contribuição do comércio intrabloco para o crescimento do comércio intra-indústria $\left(C c i i_{I N T}\right)$, observa-se que esta foi positiva e expressiva nos dois períodos considerados. No intervalo de 1991 a 1995, o comércio intra-indústria brasileiro cresceu em 30,40\% para o grupo de indústrias compreendidas nas seções IV a XVII. Neste aumento, a contribuição do comércio intrabloco foi de $13,34 \%$. Portanto, o comércio intrabloco foi responsável por $44 \%$ do aumento do comércio intra-indústria para o conjunto de seções selecionadas (tabela $9)$.

Quanto ao período compreendido entre 1995 e 1998, a contribuição do comércio intrabloco para o crescimento do comércio intra-indústria brasileiro aumentou sua participação relativamente ao período 1991/1995. Pois, considerando o grupo de seções entre IV a XVII, todo o aumento do comércio intra-indústria de $7,22 \%$ foi devido ao fluxo de comércio intrabloco (tabela 9).

Desta forma, os resultados encontrados evidenciam que cerca de $44 \%$ do crescimento do fluxo de comércio intra-indústria total multilateral brasileiro entre 1991 e 1995 foi devido à evolução do comércio intra-indústria intrabloco. Entre 1995 e 1998, a contribuição do comércio intra-industria intrabloco foi responsável por toda a evolução do comércio intra-indústria total brasileiro no caso das seções selecionadas. Esses resultados corroboram, em termos agregados, os da análise da evolução ao longo do tempo para os índices de comércio intra-indústria intra e extrabloco. 
Em termos desagregados, ou seja, ao nível das seções da NCM, observou-se que, no período de 1991 a 1995, as seções que apresentaram contribuição do comércio intrabloco $\left(C_{c i i_{I N T}}\right)$ superior a contribuição do comércio extrabloco $\left(C c i i_{E X T}\right)$ no crescimento do comércio intra-indústria total brasileiro foram: V (produtos minerais), VI (produtos das indústrias químicas e conexas), VII (plásticos e borracha), IX (madeira, cortiça e suas obras), XVI (máquinas e aparelhos, material elétrico) e XVII (material de transporte). Da mesma forma, para o período de 1995 a 1998 foram as seguintes seções: IV (produtos alimentícios, bebidas e fumo), VII (plásticos e borracha), XI (matérias têxteis e suas obras), XII (calçados, chapéus, etc.) (tabela 9).

Tabela 9

Contribuição do comércio intra e extrabloco para o crescimento do comércio intra-indústria multilateral brasileiro, em percentagem

\begin{tabular}{|c|c|c|c|c|c|c|}
\hline \multirow[b]{2}{*}{ Seções e capítulos da $\mathrm{NCM}$} & \multicolumn{3}{|c|}{$1991 / 1995$} & \multicolumn{3}{|c|}{$1995 / 1998$} \\
\hline & cii & Ccii INT & $C_{c i i} E X T$ & cii & $C c i i_{I N T}$ & $C_{E C i i} X T$ \\
\hline IV Prod. aliment., bebidas e fumo & 214,81 & 49,80 & 165,01 & $-19,20$ & 10,27 & $-29,47$ \\
\hline V Produtos minerais & $-19,01$ & 2,05 & $-21,07$ & 33,44 & $-1,24$ & 34,69 \\
\hline 27 Comb. óleos e ceras minerais & $-25,50$ & 16,15 & $-41,64$ & $-1,01$ & $-23,30$ & 22,30 \\
\hline VI Prod. indúst. Quím. e conexas & 41,33 & 33,36 & 7,98 & 25,88 & 7,53 & 18,35 \\
\hline 28 Produtos quím. inorgânicos & 32,64 & 25,98 & 6,66 & 40,38 & 8,33 & 32,05 \\
\hline 29 Produtos químicos orgânicos & 19,50 & 16,90 & 2,59 & 13,90 & $-1,38$ & 15,28 \\
\hline 30 Produtos farmacêuticos & 7,24 & 0,00 & 7,24 & 96,45 & 46,47 & 49,97 \\
\hline 31 Adubos e fertilizantes & 20,29 & 79,87 & $-59,59$ & $-16,96$ & $-24,46$ & 7,50 \\
\hline 32 Extrat. tanantes tintor. tintas & 121,92 & 52,72 & 69,19 & 61,50 & 28,84 & 32,66 \\
\hline VII Plásticos e borracha & 43,22 & 31,13 & 12,09 & 8,32 & 5,07 & 3,25 \\
\hline 39 Plásticos e suas obras & 28,94 & 35,97 & $-7,04$ & 0,26 & 3,78 & $-3,51$ \\
\hline 40 Borracha e suas obras & 64,27 & 24,00 & 40,27 & 17,63 & 6,56 & 11,07 \\
\hline VIII Peles, couros, peleteria & 6,33 & $-6,23$ & 12,55 & $-5,17$ & $-12,85$ & 7,68 \\
\hline 41 Peles (exc. peleteria) e couros & $-15,22$ & $-12,30$ & $-2,92$ & 29,62 & $-13,78$ & $-1,12$ \\
\hline IX Madeira, cortiça e suas obras & 101,08 & 70,75 & 30,32 & 76,95 & 1,48 & 75,46 \\
\hline Madeira e obras, carvão veg. & 107,15 & 81,87 & 25,28 & 8,60 & 1,35 & 77,96 \\
\hline X Pasta madeira, papel & 164,54 & 16,53 & 148,45 & 13,45 & 6,66 & 6,79 \\
\hline 47 Pasta de mad., outras mat fibros & 175,64 & 18,77 & 156,87 & 11,09 & 21,16 & $-10,06$ \\
\hline 48 Papel e cartão e suas obras & 169,22 & 13,53 & 155,69 & 4,57 & 2,25 & 2,31 \\
\hline XI Matérias têxteis e suas obras & 252,38 & 51,45 & 200,93 & $-10,58$ & $-2,10$ & $-8,48$ \\
\hline 52 Algodão & 210,74 & 76,65 & 134,09 & $-9,44$ & $-10,61$ & 1,17 \\
\hline 54 Filamentos sintét. ou artificiais & 348,50 & 43,93 & 304,58 & $-27,51$ & 2,64 & $-30,15$ \\
\hline XII Calçados, chapéus, etc. & 286,23 & 0,00 & 286,23 & $-36,31$ & $-4,01$ & $-32,30$ \\
\hline 64 Calçados, polainas e suas obras & 262,17 & 0,00 & 262,17 & $-41,65$ & $-4,64$ & $-37,01$ \\
\hline XV Metais comuns e suas obras & 103,03 & 5,87 & 97,15 & 47,81 & 4,68 & 43,14 \\
\hline 72 Ferro fundido, ferro e aço & 67,95 & 4,37 & 63,58 & 60,32 & 12,88 & 47,44 \\
\hline 73 Obras de ferro fund. ferro aço & 87,65 & 7,09 & 80,56 & 155,45 & 15,72 & 139,72 \\
\hline 76 Alumínio e suas obras & 255,22 & 22,65 & 232,56 & 60,02 & $-0,31$ & 60,33 \\
\hline 82 Ferramentas, artefatos cutelaria & 73,38 & $-9,58$ & 82,95 & 17,50 & 0,38 & 17,88 \\
\hline 83 Obras diver de metais comuns & 284,55 & 0,00 & 284,55 & 122,77 & 9,57 & 113,20 \\
\hline XVI Máq. e apar, material elétrico & 27,22 & 17,11 & 10,11 & 23,00 & 9,28 & 13,72 \\
\hline 84 Reator nucl., máq. inst. Mecân. & 27,37 & 16,62 & 10,75 & 22,52 & 9,96 & 12,56 \\
\hline 85 Máquinas apar., mat. elétricos & 26,84 & 18,37 & 8,47 & 24,25 & 7,55 & 16,70 \\
\hline XVII Material de transporte & 24,14 & 30,34 & $-6,19$ & 119,34 & 40,82 & 78,52 \\
\hline 87 Veículos autom., tratores, ciclo & 43,02 & 36,97 & 6,05 & 100,23 & 51,19 & 49,03 \\
\hline 88 Aeronav, out apr. aéreos partes & $-44,60$ & 0,00 & $-44,60$ & 470,34 & $-2,18$ & 472,52 \\
\hline Total & 30,40 & 13,34 & 17,06 & 7,22 & 7,55 & $-0,33$ \\
\hline
\end{tabular}

Fonte: Cálculos do trabalho e SECEX (1992, 1994, 1999a e b);

cii = taxa de crescimento do comércio intra-indústria total multilateral brasileiro;

Ccii $_{I N T}=$ contribuição do comércio intrabloco para o crescimento do comércio intra-indústria total;

Ccii $_{E X T}=$ contribuição do comércio extrabloco para o crescimento do comércio; intra-indústria total. 
Como pode ser observado, as seções V (produtos minerais); VI (produtos das indústrias químicas e conexas), XVI (máquinas e aparelhos, material elétrico) e XVII (material de transporte), que apresentaram para o primeiro período considerado, de 1991 a 1995, contribuição do comércio intrabloco (para o crescimento do comércio intra-indústria total) superior à contribuição do comércio extrabloco, tem esta posição invertida para o período seguinte, de 1995 a 1998.

\section{Considerações Finais}

Resguardando as limitações da análise, em termos do nível de agregação das informações empregadas, os resultados apresentados evidenciam que o crescimento do intercâmbio comercial entre o Brasil e os demais países que compõem o MERCOSUL deveu-se basicamente ao incremento no fluxo de comércio intra-indústria.

Com relação à análise da contribuição do comércio intra-indústria para o crescimento do fluxo comercial brasileiro intrabloco, observa-se que essa contribuição

foi expressiva e com uma trajetória crescente. Esta análise confirmou, assim, os resultados obtidos pela abordagem da evolução ao longo do tempo do índice de comércio intra-indústria de Grubel e Lloyd.

De forma semelhante, para a análise da contribuição do fluxo de comércio intra e extrabloco para o crescimento do comércio intra-indústria multilateral brasileiro, os resultados evidenciaram que o comércio intrabloco foi responsável por cerca de $44 \%$ do crescimento do comércio intra-indústria total multilateral brasileiro, entre 1991 e 1995, e por $100 \%$ do crescimento entre 1995 e 1998. Esses resultados confirmam as conclusões obtidas pela análise tradicional de evolução ao longo do tempo do índice de comércio intra-indústria.

Portanto, percebe-se que a implementação do MERCOSUL tem propiciado, ao longo do tempo, um maior intercâmbio de produtos de um mesmo segmento industrial, evidenciando o efeito de um aumento da especialização da produção. À princípio, este fato confirma a proposição de que a liberalização comercial gera um aumento nos índices de comércio intra-indústria.

Desta forma, os ganhos incorridos pela economia brasileira em decorrência do aumento no fluxo de comércio intra-indústria, podem ser observados por dois ângulos de análise. Pelo lado da demanda, o comércio intra-indústria acarretaria um aumento de bem-estar em termos de satisfação das necessidades e gostos, pois a maior disponibilização de produtos possibilitaria um maior leque de escolha.

Pelo lado da produção, o aumento no comércio intra-indústria possibilitaria, através do ganho de escala e diferenciação de produtos, a especialização das firmas em poucas linhas de produção. Logo, esta maior especialização propiciaria 
um incremento da produtividade e eficiência, traduzindo-se em uma maior competitividade internacional para o país.

Assim, o aprofundamento do estudo do comércio intra-indústria torna-se essencial para a definição da melhor estratégia de política comercial em um cenário internacional caracterizado por grandes blocos econômicos, onde é crescente o fluxo comercial de produtos de um mesmo segmento industrial. Neste sentido, uma sugestão de trabalhos futuros seria no sentido da investigação dos fatores determinantes do comércio intra-indústria no âmbito de acordos regionais de integração econômica.

\section{Referências}

Albuquerque, C. R. \& Fernandes, C. L. L. (1999). Impactos da liberalização comercial no perfil do comércio exterior brasileiro. In Anais. Belém. ANPEC (em CD-ROM).

Balassa, B. (1986). Intra-industry specialization: A cross-country analysis. European Economic Review, (30):27-42.

Bergstrand, J. H. (1983). Measurement and determinants of intra-industry international trade. In Tharakan, P. K. M. E., editor, Intra-Industry Trade: Empirical and Methodological Aspects, pages 201-253. Amsterdam: North-Holland.

Bergstrand, J. H. (1990). The Heckscher-Ohlin-Samuelson model, the Linder hypothesis and the determinants of bilateral intra-industry trade. The Economic Journal, 100:1216-1229.

Brülhart, M. (1994). Marginal intra-industry trade: Measurement and relevance for the pattern of industrial adjustment. Weltwirtschaftliches Archiv, 130:601613.

Gavelin, L. \& Lundberg, L. (1983). Determinants of intra-industry trade: Testing some hypotheses on Swedish trade data. In Tharakan, P. K. M. E., editor, Intra-Industry Trade: Empirical and Methodological Aspects, pages 161-200. Amsterdam: North-Holland.

Globerman, S. (1992). North American trade liberalization and intra-industry trade. Weltwirtschaftliches Archiv, 128:487-497. 
Greenaway, D., Hine, R., \& Milner, C. R. (1995). Vertical and horizontal intraindustry trade: A cross insustry analysis for the United Kingdon. The Economic Journal, 105:1504-1518.

Greenaway, D. \& Milner, C. (1999). Industrial structure and Australia-UK intraindustry trade. The Economic Record, 75(228):19-27.

Greenaway, D. \& Milner, C. R. (1989). Trade theory and the less developed countries. In (Ed.), G., editor, Surveys in Development Economics, pages 1155. Basil Blackwell, Oxford.

Grubel, H. G. \& Lloyd, P. J. (1975). Intra-Industry Trade: The Theory and Measurement of International Trade in Differentiated Products. Macmillan, London.

Havrylyshyn, O. \& Civan, E. (1983). Intra-industry trade and the stage of development: A regression analysis of industrial and developing countries. In Tharakan, P. K. M. E., editor, Intra-Industry Trade: Empirical and Methodological Aspects, pages 111-140. Amsterdam: North-Holland.

Helpman, E. (1981). International trade in the presence of product differentiation, economies of scale and monopolistic competition: A Chamberlim-HeckscherOhlin approach. Journal of International Economics, 11:305-340.

Hidalgo, A. B. (1993). O intercâmbio comercial brasileiro intra-indústria: Uma análise entre indústrias e entre países. Revista Brasileira de Economia, $47(2): 243-264$.

Krugman, P. R. (1981). Intra-industry specialization and gains from trade. Journal of Political Economy, 89(5):959-973.

Lerda, S. C. M. S. (1988). Comércio internacional intra-industrial: Aspectos teóricos e algumas evidências, com aplicação ao caso brasileiro. Brasília: UNB. (Dissertação de Mestrado - Universidade de Brasília).

Machado, J. B. M. \& Markwald, R. A. (1997). Dinâmica recente do processo de integração do Mercosul. In Anais, pages 723-742. Recife: ANPEC.

Machado, J. B. M. \& Markwald, R. A. (1998). Padrões de comércio intra e extraMercosul: Alvos para uma política industrial do Mercosul. Rio de Janeiro: FUNCEX (Texto para Discussão N. 141, novembro), 21 p.

Menon, J. \& Dixon, P. B. (1996). Regional trading agreements and intra-industry trade. Journal of Economic Integration, 11(1):1-20. 
Menon, J. \& Dixon, P. B. (1997). Measures of intra-industry trade as indicators of factor market disruption. The Economic Record, 73(222):233-247.

Oliveira, M. H. (1986). Evidências empíricas do comércio intra-indústria. Revista Brasileira de Economia, 40(3):211-232.

Secretaria da Receita Federal (1990). Comércio exterior do Brasil: Importação. Brasília: Receita Federal, Ano 19, Vol. III.

Secretaria da Receita Federal (1991). Comércio exterior do brasil: Importação. Brasília: Receita Federal, Ano 20, Vol. III.

Secretaria de Comércio Exterior (1999a). Balança comercial brasileira. Rio de Janeiro: MICT/SECEX (Tabelas para donwload: http://www.mdic.gov.br/secex/estatistica).

Secretaria de Comércio Exterior (1999b). Balança comercial brasileiraMercosul. Rio de Janeiro: MICT/SECEX (Tabelas para donwload: http://www.mdic.gov.br/secex/estatistica).

Secretaria de Comércio Exterior - SECEX (1992). Balança comercial brasileira. Rio de Janeiro: MICT/SECEX.

Secretaria de Comércio Exterior - SECEX (1994). Intercâmbio comercial: BrasilMercosul. Rio de Janeiro: MICT/SECEX. 19 p.

Shelburne, R. C. (1994). Changing trade patterns and the intra-industry index: A note. Weltwirtchaftliches Archiv, 130:829-833.

Tarakan, P. K. M. (1983). The economics of intra-industry: A survey. In Tharakan, P. K. M. E., editor, Intra-Industry Trade: Empirical and Methodological Aspects, pages 1-34. Amsterdam: North-Holland.

Vasconcelos, C. R. F. (2000). O comércio brasil-mercosul na década de 90: Uma análise pelas óticas da intensidade fatorial, comércio intra-indústria e criação e desvio de comércio. Recife: Universidade Federal de Pernambuco (Tese de Doutorado), 221p. 